\title{
Gerenciamento da Produção de Energia e Controle de Inundação: Foz do Areia no Rio Iguaçu
}

\author{
Miriam R. M. Mine \\ Universidade Federal do Paraná - Caixa Postal 19011 \\ 81531-990Curitiba,PR - mrmine.dhs@ufpr.br \\ Carlos E. M. Tucci \\ Instituto de Pesquisas Hidráulicas - Universidade Federal do Rio Grande do Sul - Caixa Postal 15029 \\ 91501-970 PortoAlegre, RS - carlos.tucci@ufros.br \\ Recebido: 04/02/02 - revisão: 28/06/02 - aceito: 05/09/02
}

\section{RESUMO}

A operação de um reservatório para geração elétrica busca a maximização do nivel e da vazão, o que pode gerar conflitos a montante e jusante do aproveitamento devido às inundações. Para gerenciar estes objetivos conflitantes é necessário um sistema da previsão de afluência de vazão ao reservatório integrado com a sua operação. Este sistema deve minimizar os impactos das inundações e maximizar a produção energética.

Neste estudo é apresentada a metodologia de previsão de vazão de afluência em combinação com a operação de uma usina bidrelétrica que atenda os dois objetivos citados. A metodologia proposta utiliza um modelo ARIMA para a previsão de afluência da bacia afluente a montante da entrada do lago, onde os processos possuem maior memória e um modelo semi-conceitual (modelo chuva-vazão IPH II) para a parcela da bacia de contribuição direta ao lago do reservatório. Uma das importantes incertezas da previsão é a previsão da precipitação utilizada no modelo chuva-vazão citado. Neste caso, algumas alternativas foram estudadas: a) a chuva cessa a partir do instante em que se faz a previsão; b) a previsão de chuva é conhecida; c) usa-se uma previsão estocástica de chuva.

Associada à previsão, foi desenvolvido um modelo de operação do reservatório que permitisse maximizar a produção de energia e garantir o cumprimento das restrições operacionais de segurança do reservatório e para a população de montante e jusante.

Esta metodologia, apesar de utilizada em específico para o reservatório de Foz do Areia, representa um condicionante freqüiente encontrado em diferentes reservatórios energéticos brasileiros. No caso de Foz. do Areia, no rio Iguaçu, os resultados mostraram que a previsão realizada permite melhorar o atendimento das restrições e recuperação dos niveis do reservatório.

Palavras-chave: previsão; tempo real; reservatório.

\section{INTRODUÇÃO}

A operação de reservatórios hidrelétricos é realizada procurando-se manter o volume de água o mais elevado possível. Durante a época chuvosa, é usual rebaixar o nível do reservatório e criar um volume vazio para segurança da barragem e para o controle de inundações a montante e à jusante. Este volume é denominado volume de espera.

Esse volume permite controlar as inundações mais freqüentes à jusante do reservatório e minimizar o efeito do remanso sobre regiões localizadas a montante.

O Setor Elétrico Brasileiro tem alocado volumes de espera em reservatórios do sistema interligado, através do método da curva volume versus duração (GCOI, 1991). Entretanto, diversas dificuldades de ordem prática têm sido encontradas na implantação do método:

- em conseqüência das variações amostrais, a curva volume versus duração pode não ser côncava;

- o método informa somente um único volume de espera para toda a estação chuvosa, portanto, não considera a variação do potencial da cheia com o decorrer da estação, permanecendo constante durante todo o período chuvoso. Esta solução, na medida em que existem interesses conflitantes, não é eficiente. Em regiões com sazonalidade bem definida, o risco para o qual o volume de espera foi dimensionado, só se verifica no início da estação chuvosa, e vai diminuindo conforme o período úmido se aproxima do seu final. Logo, a alocação desse volume constante superdimensiona a proteção desejada para o controle de cheias e penaliza a geração de energia para a estação seca que se segue.

Visando superar os problemas apresentados acima, Kelman (1983) propôs o método das trajetórias críticas, representando uma significativa evolução, dado que o método resolve simultaneamente o problema de determinação e alocação de volumes de espera, permitindo determinar, para cada dia da estação chuvosa, o volume de espera para uma probabilidade de emergência previamente determinada. O método utiliza um algoritmo recursivo sobre as vazões naturais médias diárias, a partir do último dia da estação chuvosa do local a ser estudado.

Os métodos citados acima estão fundamentados em uma abordagem estatística, e são empregados com maior 
eficiência em reservatórios situados em regiões com sazonalidade definida, onde o ano hidrológico inicia em outubro, início do período chuvoso. A região Sudeste do Brasil caracteriza-se por um regime desse tipo, o mesmo não acontecendo com a região Sul, onde podem ocorrer inundações tanto no inverno como no verão.

Neste estudo é apresentado um método conjugado de previsão em tempo real e de operação, buscando explorar a integração entre a modelagem hidrológica para previsão de afluências a reservatórios, com modelos de simulação da operação, que auxiliam na tomada de decisão, de tal forma a constituir um sistema único, capaz de prever deterministicamente os volumes de espera em tempo real a serem alocados para o controle de cheias

\section{ESTRUTURA METODOLÓGICA}

Um sistema de previsão e operação de um reservatório (ou sistema de reservatórios) em tempo real pode ser estruturado nos seguintes módulos:

- previsão da precipitação;

- previsão da vazão;

- operação do reservatório ou do sistema.

Os dois primeiros modelos se referem à previsão das variáveis hidrológicas e o último utiliza as informações geradas em tempo real e define as operações do reservatório em função dos condicionantes existentes. A Figura 1 apresenta a estrutura de simulação adotada, mostrando de forma esquemática a interligação entre os módulos mencionados acima. A seguir são descritos os modelos citados.

\section{Previsão de precipitação}

A previsão quantitativa da precipitação, em tempo real, no espaço, ainda apresenta grandes incertezas e nem sempre estão disponíveis no intervalo de tempo necessário para os modelos hidrológicos. Neste estudo, procurou-se identificar os dois limites e seu impacto sobre a previsão, ou seja, o uso de precipitação nula futura e o uso da precipitação verdadeira. Além disso, como alternativa intermediária, utilizou-se as informações de persistência do processo da chuva para a sua previsão.

$\mathrm{Na}$ literatura, encontram-se muitos modelos desenvolvidos para representar séries temporais de chuva; e os que fornecem resultados mais promissores são aqueles baseados no processo de Poisson. Estes processos variam em complexidade desde modelos mais simples como o Poisson Rectangular Pulse - PRP até modelos mais sofisticados que caracterizam cada evento por um cluster de pulsos como Neyman-Scott White Noise - NSWN, Neyman-Scott Rectangular Pulses - NSRP e Bartlett-Lewis Rectangular Pulses BLRP (Obeysekera et al., 1987).

Apesar desses modelos representarem satisfatoriamente o processo estocástico da chuva, a sua formulação

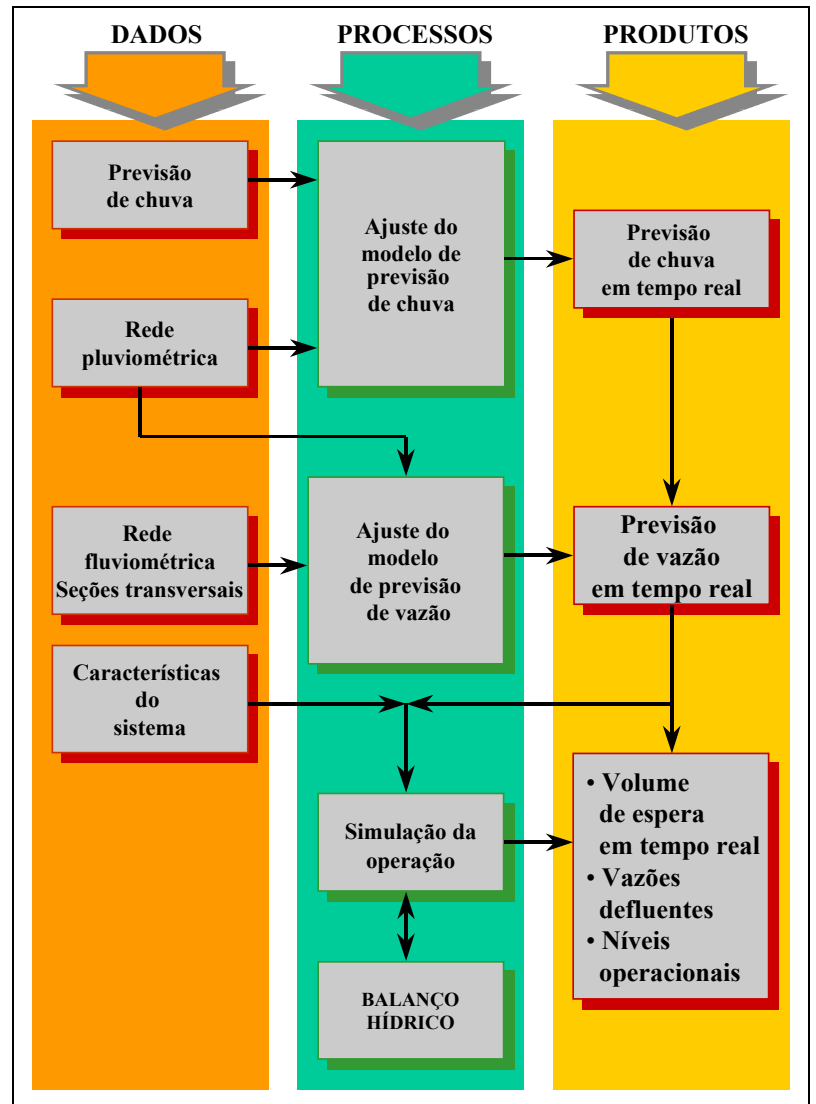

Figura 1. Estrutura de previsão e simulação.

para previsão em tempo real é bastante complexa, o que levou à busca de uma formulação mais simples e de aplicação prática. A adoção de modelos ARMA de baixa ordem para a previsão de chuvas horárias foi motivada por estudos realizados por Obeysekera et al. (1987). Os autores investigaram a modelagem de curto termo da chuva, baseada em modelos do tipo PRP, NSWN e NSRP e mostraram que a estrutura de correlação de um processo de chuva média é equivalente à estrutura de correlação de processos ARMA de baixa ordem. A Figura 2 ilustra as regiões admissíveis para as autocorrelações $\rho_{1}$ e $\rho_{2}$ de um processo ARMA $(1,1)$ (Box \& Jenkins, 1976) e dos processos PRP e NSWN.

O processo de identificação do modelo foi apresentado por Box \& Jenkins (1976), onde a ferramenta fundamental na estimativa dos parâmetros é a função de autocorrelação da série temporal. De forma geral o modelo é representado por:

$$
Z_{t}=\sum_{j=1}^{p} \phi_{j} Z_{t-j}+a_{t}-\sum_{j=1}^{q} \theta_{j} a_{t-j}
$$

onde: $Z_{\mathrm{t}}$ são desvios em relação à média $\mu$ do processo; $\phi_{\mathrm{j}} \mathrm{e}$ $\theta_{\mathrm{j}}$ são parâmetros auto-regressivos e de médias móveis respectivamente; $a_{t}$ são ruídos brancos e t é o tempo em horas.

Esse modelo é válido para processos estacionários e a chuva é um processo tipicamente não-estacionário, com 


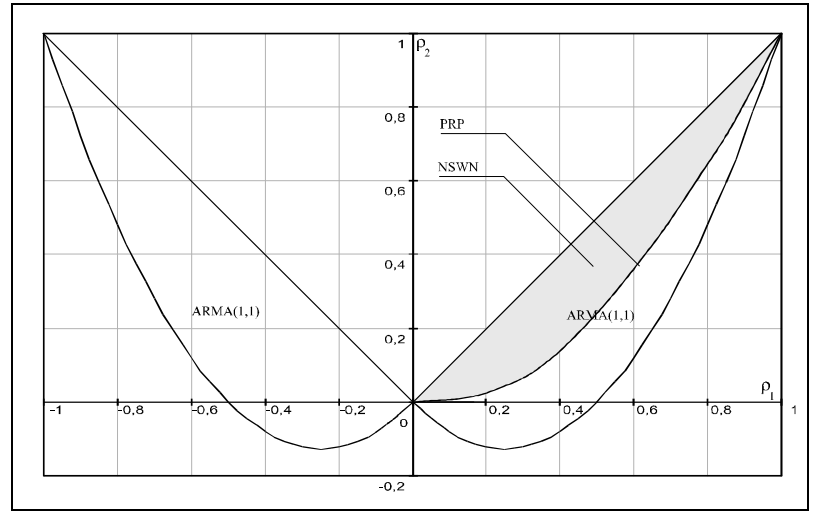

Figura 2. Estrutura de correlação dos processos ARMA (1,1), PRP e NSWN.

distribuições de probabilidades assimétricas. Esta é uma limitação destes modelos, podendo não se adequar perfeitamente a chuvas horárias, tendo em vista a dificuldade em se encontrar transformações nos dados originais que resultem em processos estacionários com distribuições simétricas (normal), devido ao grande número de zeros (dias sem chuva) nas séries temporais em questão.

\section{Previsão de vazões}

Um reservatório de produção de energia geralmente possui como característica uma bacia de contribuição de grande porte $\left(>10.000 \mathrm{~km}^{2}\right)$. Na entrada superior do reservatório a seção drena grande parte da bacia e, portanto, possui maior persistência nas vazões ao longo do tempo, enquanto que a bacia de contribuição direta do lago influi rapidamente no nível do reservatório devido ao seguinte:

- a bacia contribuinte tem pequeno tempo de concentração;

- a vazão quanto entra no lago, contribui quase instantaneamente ao nível do reservatório, devido à alta celeridade da onda (grande profundidade);

- quando o lago é muito grande, a precipitação direta pode representar um volume importante, pois todo o valor precipitado se converte em volume escoado.

Desta forma, quando a contribuição direta ao lago influi de forma significativa na operação do volume de espera, é necessário que esta contribuição direta ao lago seja prevista com alguma antecedência.

A metodologia adotada neste estudo foi a seguinte:

- modelo empírico (estocástico) para a previsão de afluências a montante do lago;

- modelo determinístico chuva-vazão para previsão da contribuição direta ao lago.

Previsão de vazões em seção a montante do reservatório - Em bacias hidrográficas grandes $\left(>10.000 \mathrm{~km}^{2}\right)$,
Tabela 1. Parâmetros do modelo IPH II.

\begin{tabular}{|c|c|c|}
\hline Parâmetro & Descrição & Unidades \\
\hline $\mathrm{R}_{\max }$ & $\begin{array}{l}\text { Capacidade máxima do } \\
\text { reservatório de intercepção }\end{array}$ & $\mathrm{mm}$ \\
\hline $\mathrm{S}_{\max }$ & $\begin{array}{l}\text { Teor máximo de } \\
\text { umidade no solo }\end{array}$ & $\mathrm{mm}$ \\
\hline $\mathrm{I}_{\mathrm{O}}$ & $\begin{array}{l}\text { Capacidade de infiltração } \\
\text { para } t=0\end{array}$ & $\mathrm{~mm} \mathrm{~h}^{-1}$ \\
\hline $\mathrm{I}_{\mathrm{b}}$ & $\begin{array}{l}\text { Capacidade de infiltração } \\
\text { mínima }\end{array}$ & $\mathrm{mm} \mathrm{h}^{-1}$ \\
\hline k ou h & $\begin{array}{l}\text { Parâmetro empírico } \\
\text { função do tipo de solo }\end{array}$ & $\mathrm{h}^{-1}$ \\
\hline$t_{p}$ & $\begin{array}{l}\text { Tempo de } \\
\text { percurso }\end{array}$ & $\mathrm{H}$ \\
\hline$K_{\text {sup }}$ & $\begin{array}{l}\text { Coef. de recessão do } \\
\text { escoamento superficial }\end{array}$ & $\mathrm{H}$ \\
\hline$K_{\text {sub }}$ & $\begin{array}{l}\text { Coef. de recessão do } \\
\text { escoamento subterrâneo }\end{array}$ & $\mathrm{H}$ \\
\hline IMP & $\begin{array}{l}\text { Percentagem de área } \\
\text { impermeável }\end{array}$ & $\%$ \\
\hline
\end{tabular}

caracterizadas por hidrogramas de cheias com uma lenta variabilidade temporal, os modelos do tipo ARIMA têm apresentado resultados satisfatórios para a previsão de afluências devido às características de autocorrelação da vazão. Estes modelos apresentam as vantagens de utilizar apenas informações de vazões no próprio local de interesse e utilizam para as previsões uma simples equação recursiva, muito semelhante à apresentada para os modelos estacionários, o que os torna facilmente operacionalizáveis.

Os fundamentos dos modelos não estacionários ARIMA o leitor interessado poderá encontrá-los nas referências Box \& Jenkins (1976) e Mine (1984), onde os autores expõem de forma detalhada a metodologia de identificação, estimativa e verificação, que constituem as principais etapas da construção desses modelos.

Previsão de vazões na bacia intermediária - $\mathrm{O}$ modelo de transformação chuva-vazão IPH II, desenvolvido no Instituto de Pesquisas Hidráulicas da Universidade Federal do Rio Grande do Sul, foi utilizado na simulação da bacia intermediária de contribuição direta ao lago. Este modelo foi descrito por vários autores (Tucci et al., 1981).

A base principal do modelo IPH II é um algoritmo de separação do escoamento desenvolvido por Berthelot (1970). O autor utiliza a equação da continuidade em combinação com a equação de Horton (1937) e uma função empírica para percolação. É composto dos seguintes algoritmos: a) perdas por evaporação e intercepção; b) separação dos escoamentos; c) propagação dos escoamentos superficial e subterrâneo; d) otimização dos parâmetros (quando for de interesse do usuário).

Os parâmetros utilizados no modelo estão apresentados na Tabela 1. Dos parâmetros a serem ajustados, o coeficiente de depleção do escoamento subterrâneo $\mathrm{K}_{\text {sub }}$ 
pode ser estimado a partir da recessão dos hidrogramas observados. Este parâmetro é muito pouco sensível, principalmente para simulação de cheias isoladas. O parâmetro $\mathrm{R}_{\max }$ também é pouco sensível e pode ser facilmente ajustado através da análise dos volumes observados e simulados pelo modelo. $\mathrm{Na}$ realidade, restam quatro parâmetros mais sensíveis para o ajuste: $\mathrm{I}_{\mathrm{o}}, \mathrm{I}_{\mathrm{b}}$, h e $\mathrm{K}_{\text {sup. Este último }}$ representa o tempo (em número de intervalos) entre o centro do hietograma (após a aplicação do histograma tempo-área) e o centro de massa do hidrograma.

\section{Simulação da operação do reservatório}

As previsões de afluências obtidas pelo modelo conjugado estocástico-determinístico, juntamente com as restrições físicas e operacionais da usina, permitem definir a regra de operação do reservatório em termos de volumes defluentes e de níveis a serem respeitados a montante, com a utilização de um modelo hidrodinâmico de propagação em canal.

A simulação da operação deve atender às restrições físicas e operacionais da usina: a) níveis ou volumes máximos e mínimos que são impostos pelas características do projeto e pelas normas de segurança da barragem; b) descargas limites, que são função dos volumes armazenados no reservatório e das características de operação das estruturas hidráulicas (comportas, vertedouros e turbinas); c) taxas de máxima variação de defluências durante a operação normal; d) restrições de níveis a serem respeitados em seções localizadas a montante do reservatório, e que, portanto, estão sujeitas ao efeito do remanso.

O procedimento para definição da política de operação de reservatórios com objetivos conflitantes é feito, neste trabalho, de forma iterativa, isto é, as simulações são feitas para cada intervalo de tempo $(\Delta t=1)$ dentro do horizonte de previsão $t$ até $t+\tau$. As decisões operacionais são realizadas para intervalos de tempo, $\delta$, no máximo, iguais ao horizonte de previsão. Os dados hidrológicos disponíveis do último horizonte de decisão são incorporados ao sistema operacional, de tal forma que o estado do sistema bacia hidrográfica-reservatório possa ser atualizado em tempo real.

O fluxograma simplificado da Figura 3, adaptado de Silveira (1996), ilustra o procedimento apresentado a seguir:

1. Inicia-se a simulação no tempo $t$ onde devem ser conhecidos, além das informações hidrológicas anteriormente mencionadas, o estado do reservatório, volume $\mathrm{S}(\mathrm{t})$, a curva cota-volume do reservatório, a curva de descarga do vertedouro, o hidrograma de vazões turbinadas previstas pelo despacho de carga do tempo $t$ até $\mathrm{t}+\tau$, e o intervalo de tempo de cálculo $(\Delta t=1)$.

2. Através da simulação do modelo hidrológico combinado prevê-se o volume no reservatório para o horizonte de previsão $\tau$.

3. Se o volume previsto para o tempo $t+\tau$ for menor que o nível máximo normal de operação $\left(\mathrm{S}_{\max }\right)$, o vo- lume vertido será nulo até que este nível seja atingido. Caracteriza-se uma fase de enchimento do reservatório e o volume defluente, $\mathrm{Q}_{\mathrm{D}}(\mathrm{t})$, será dado somente pelo volume turbinado, $\mathrm{Q}_{\mathrm{T}}(\mathrm{t})$.

4. Se o volume previsto para o tempo $t+\tau$ for igual ao máximo normal de operação, $\mathrm{S}_{\max }$, haverá vertimentos em $t$, correspondentes à diferença entre os volumes afluentes e turbinados previstos. Caracteriza-se, portanto, uma fase de manutenção do nível do reservatório.

5. Se o volume previsto for maior que o máximo normal de operação, $\mathrm{S}_{\max }$, haverá vertimentos em t, caracterizando uma fase de esvaziamento do reservatório. Neste caso há necessidade de criar um volume para amortecer a onda de cheia, o que é feito rebaixandose o nível máximo normal operativo para o nível meta do volume de espera, determinado pela previsão de afluências ao reservatório. A vazão a ser vertida em $t$ será igual ao volume que ultrapassou o armazenamento máximo normal de operação, $\mathrm{S}_{\max }$, acrescido do volume necessário para atingir o volume meta, uma vez atendidas as necessidades de geração do sistema. Logo, a vazão vertida será determinada pela Equação (2) procurando-se evitar que sejam rompidas as condições de armazenamento e defluências máximos (incluindo as taxas de máximas defluências para cada passo de cálculo, $\Delta \mathrm{t}$, até o tempo $\mathrm{t}+\tau$ ), considerando, também, níveis de alerta em seções situadas a montante do reservatório. Cabe, portanto, dizer que, o nível meta do volume de espera é obtido iterativamente, dentro do horizonte de previsão, para cada intervalo de tempo $(\Delta t=1)$, em virtude das características físicas e restrições operacionais do reservatório.

$$
\mathrm{Q}_{\mathrm{V}}(\mathrm{t}) \Delta \mathrm{t}=\hat{\mathrm{S}}(\mathrm{t}+1)-\mathrm{S}_{\max }-\mathrm{Q}_{\mathrm{T}}(\mathrm{t}) \Delta \mathrm{t}
$$

onde: $\mathrm{S}_{\max }$ é o volume correspondente ao nível meta do volume de espera.

Inicialmente, determina-se o volume vertido de acordo com a Equação (2). Caso as restrições operacionais sejam verificadas, mantém-se a descarga vertida determinada por esta equação; caso contrário, o volume de água que excedeu a restrição é redistribuído entre os vertimentos do próximo intervalo de decisão.

Conhecendo-se, assim, as vazões afluentes ao reservatório, previstas com uma antecedência $\tau$, pode-se determinar uma descarga mínima que deve ser vertida em $t$, de tal modo que o volume armazenado não exceda $S_{\max }$ e a descarga defluente não exceda $\mathrm{Q}_{\mathrm{D}_{\max }}$ entre $\mathrm{t}+1$ e $\mathrm{t}+\tau$.

6. Repetem-se os itens de (1.) até (5.) com as mesmas restrições físicas e operacionais para cada intervalo de tempo $j$, enquanto a condição de operação for caracterizada como operação normal, isto é, enquanto não houver perspectiva que o volume da cheia esgote o volume de espera e rompa restrições operacionais, caso contrário, a operação será caracterizada como operação em emergência. 


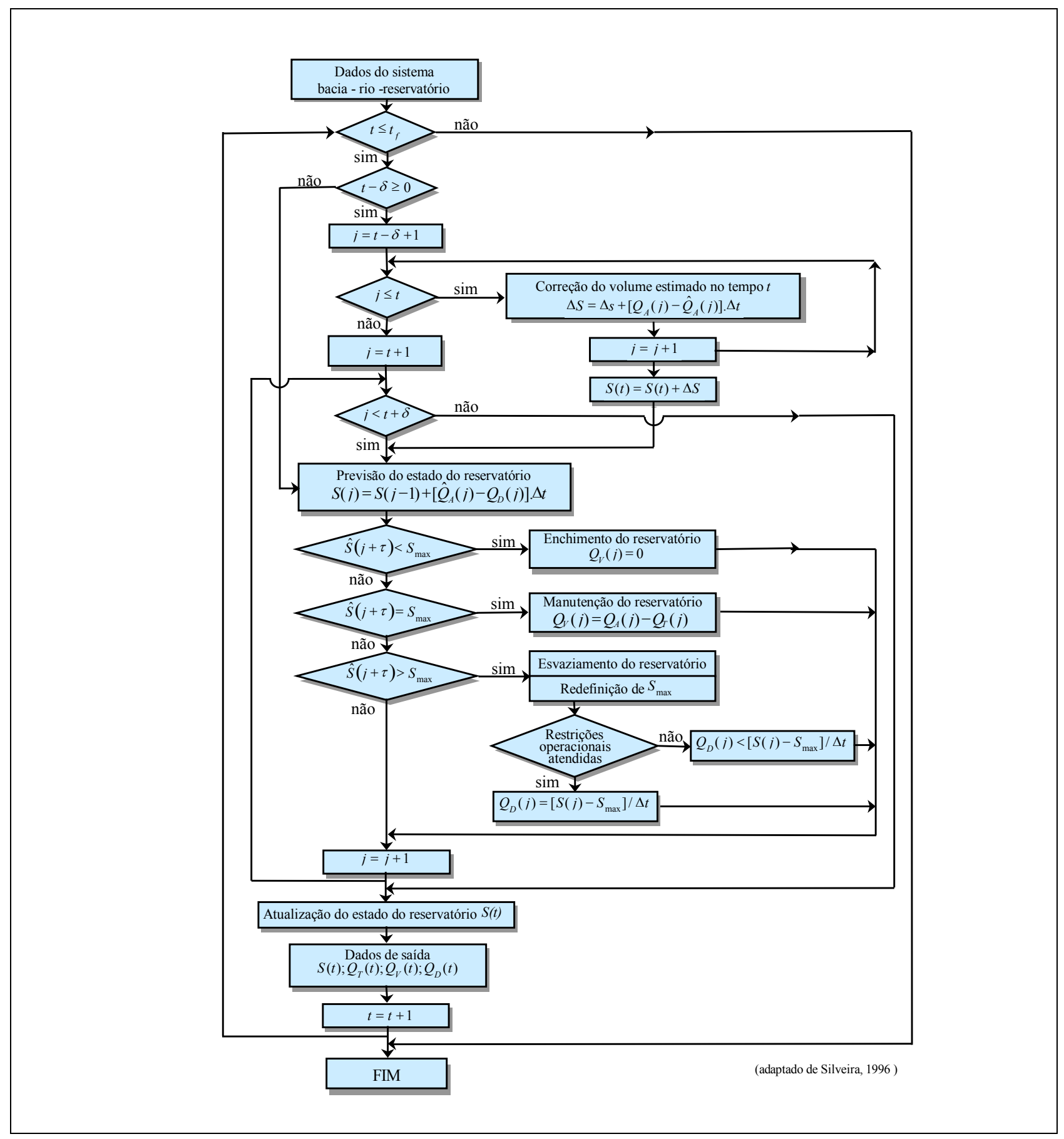

Figura 3. Fluxograma simplificado da simulação da operação.

7. Na operação em emergência, se houver folga na capacidade de vertimento do vertedouro, $\mathrm{S}_{\max }$ será redefinido como um valor entre o armazenamento máximo normal e o armazenamento máximo maximorum. O vertimento nesta condição será igual à diferença entre a vazão máxima de restrição e a vazão turbinada prevista, até que seja rompida a restrição física.

8. Caso o volume da cheia esgote a nova condição de armazenamento máximo, rompe-se a restrição de va- zão máxima e o vertimento será igual à diferença entre a vazão afluente e a vazão turbinada previstas.

9. Depois de calcular o volume que será vertido, resultado de uma das situações acima, determina-se o estado do reservatório para o próximo intervalo de tempo. As diferenças entre volumes reais e volumes previstos são compensadas em cada intervalo de decisão.

10. Repetem-se todos os itens anteriores, para cada intervalo de tempo ti até tf, correspondente ao período chuvoso. 


\section{RESULTADOS}

\section{Sistema Foz do Areia no rio Iguaçu}

O rio Iguaçu é um dos principais afluentes do curso médio do rio Paraná. Desde suas nascentes, próximas à cidade de Curitiba, até sua foz, no rio Paraná, drena uma bacia de $66800 \mathrm{~km}^{2}$, localizada entre os paralelos $25^{\circ} 00^{\prime}$ e $27^{\circ} 00^{\prime}$ de latitude sul e os meridianos 5430' e 4900’ de longitude oeste. Em Foz do Areia a área da bacia drenada é de $29800 \mathrm{~km}^{2}$.

O relevo é bastante irregular, e uma característica interessante do rio Iguaçu é a existência, no seu trecho superior, de vales amplos e de baixa declividade, proporcionando boas possibilidades de armazenamento, seguindo-se no seu trecho médio e inferior, vales rochosos estreitos e declividades mais acentuadas, com quedas concentradas, propiciando bons locais para barramento (Figuras 4 e 5). Estes aspectos tornam o rio Iguaçu particularmente atraente para a implantação de aproveitamentos hidrelétricos.

Em Foz do Areia, no trecho médio do rio Iguaçu, a topografia caracteriza-se pela existência de um vale encaixado e profundo, onde a largura do rio é pequena, variando de $80 \mathrm{~m}$ a $150 \mathrm{~m}$, e os taludes das margens são bastante íngremes.

A geologia de Foz do Areia consiste de um substrato de rochas basálticas recoberto por solos coluviais e residuais. O local dista aproximadamente $80 \mathrm{~km}$ de Porto Vitória, onde o rio Iguaçu secciona a escarpa da Serra Geral e penetra na região das rochas basálticas. Desta forma, o reservatório está situado sobre basaltos até este local e sobre arenitos finos da formação Botucatu na maior parte do trecho a montante.

As condições climáticas da região Sul do Brasil, que inclui a bacia do rio Iguaçu, são de um modo geral determinadas pelo movimento relativo das massas de ar que circulam sobre a região.

Esses movimentos são influenciados pela posição relativa dos anti-ciclones sobre os oceanos Pacífico e Atlântico e do centro de baixa pressão localizado sobre o continente. Esses centros variam de posição e intensidade ao longo do ano de maneira irregular, acarretando como conseqüência uma distribuição errática ao longo do ano das principais características climáticas da região, tais como condições de temperatura, pressão, umidade do ar e precipitação. A temperatura média anual é da ordem de $16^{\circ} \mathrm{C}$ em União da Vitória. A evaporação e evapotranspiração também devem apresentar variações apreciáveis. A falta de observações diretas limita o conhecimento desses parâmetros. Os poucos dados disponíveis indicam, para a bacia do rio Iguaçu, a ocorrência de valores entre $750 \mathrm{~mm} \mathrm{ano}^{-1} \mathrm{e}$ $800 \mathrm{~mm} \mathrm{ano}^{-1}$ para evaporação do lago e evapotranspiração média da ordem de $800 \mathrm{~mm}^{2} \mathrm{ano}^{-1}$ (COPEL, 1995).

A precipitação pluvial é a variável hidrológica melhor conhecida na bacia, sendo muito importante a contribuição pluviométrica na bacia incremental entre União da Vitória e Foz do Areia. A precipitação média anual sobre a bacia

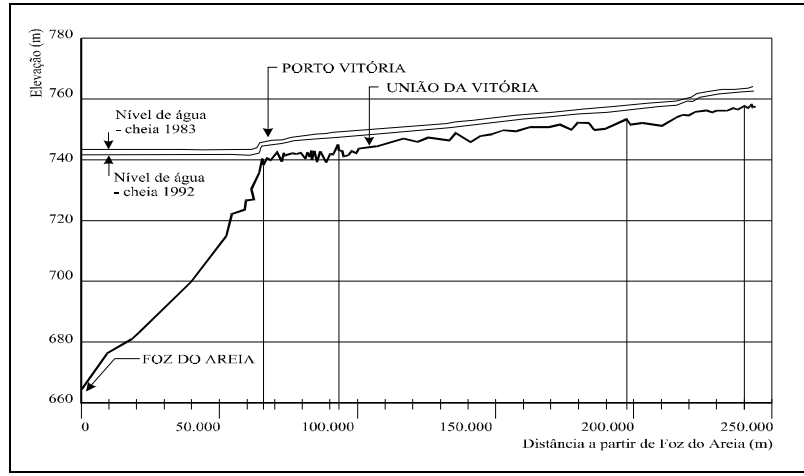

Figura 4. Perfil do rio Iguaçu no local do estudo.

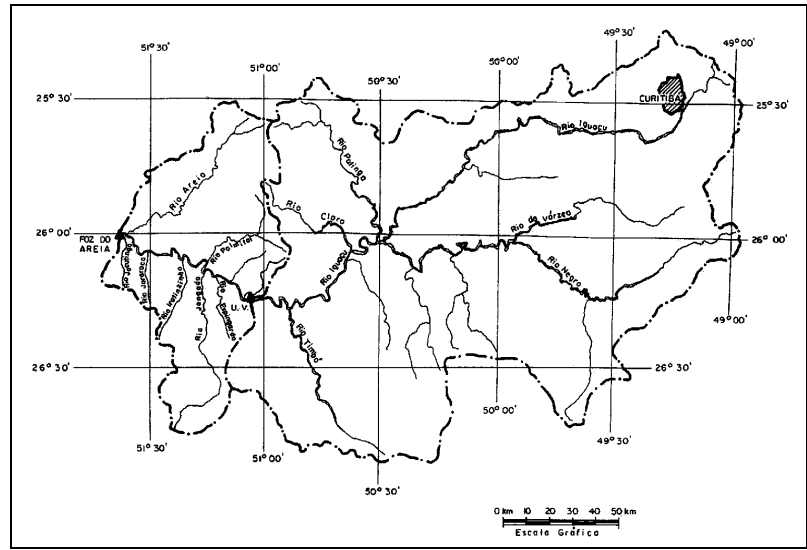

Figura 5. Mapa da bacia hidrográfica

do rio Iguaçu é da ordem de $1500 \mathrm{~mm}$ ano ${ }^{-1}$, e a distribuição da chuva é bastante irregular no tempo e no espaço, consequentemente não há um período úmido bem definido.

Descrição do aproveitamento hidrelétrico - A Usina de Foz do Areia, denominada "Usina Governador Bento Munhoz da Rocha Netto" (COPEL, 1995), possui uma potência instalada de 1674 MW com possibilidade de ampliação para $2511 \mathrm{MW}$, e está localizada no rio Iguaçu, no Estado do Paraná, entre os municípios de Bituruna e Pinhão. As coordenadas geográficas são, aproximadamente, $26^{\circ} 03^{\prime}$ de latitude sul e 51\%41' de longitude oeste. A usina dista, em linha reta, cerca de $250 \mathrm{~km}$ da cidade de Curitiba, em direção sudoeste e $5 \mathrm{~km}$ da foz do rio Areia, para jusante e situa-se a $750 \mathrm{~m}$ à jusante da confluência deste rio.

$\mathrm{O}$ aproveitamento compreende uma barragem de enrocamento com face de concreto com uma altura máxima de $160 \mathrm{~m}$, comprimento da crista de $828 \mathrm{~m}$ e volume total de cerca de $14.000 .000 \mathrm{~m}^{3}$; um vertedouro tipo calha dotado de quatro comportas segmento de $14,50 \mathrm{~m}$ de largura por 19,45 m de altura cada e com uma capacidade de descarga de $10250 \mathrm{~m}^{3} \mathrm{~s}^{-1}$.

O reservatório, criado pela barragem, tem uma área de $153 \mathrm{~km}^{2}$ no nível correspondente à cota $744 \mathrm{~m}$. O volume total do reservatório é de $6066 \times 10^{6} \mathrm{~m}^{3}$, dos quais, com uma depleção de $47 \mathrm{~m}$, resulta um volume útil da 
ordem de $4300 \times 10^{6} \mathrm{~m}^{3}$, para regularizar $59 \%$ da vazão média de longo termo $\left(544 \mathrm{~m}^{3} \mathrm{~s}^{-1}\right)$.

A energia gerada em Foz do Areia é absorvida pelo sistema interligado das regiões Sul, Sudeste e Centro Oeste do Brasil. A operação interligada da usina é muito importante para o Setor Elétrico, tendo em vista que as marcantes diferenças do regime hidrológico das regiões Sul e Sudeste proporcionam consideráveis ganhos de energia garantida ao sistema.

O potencial energético total em Foz do Areia é estimado em 750 MW médios, valor este que também representa a máxima energia firme de ser obtida, admitindo-se que a vazão do rio Iguaçu possa ser totalmente utilizada, quer por regularização total, quer por interligação com os sistemas regionais e com o sistema global.

\section{Previsão de vazões em União da Vitória}

As previsões de vazões em União da Vitória foram feitas pelos modelos auto-regressivos de segunda ordem nas primeiras diferenças, estimados por Mine (1986), com base em enchentes ocorridas no período 1939 a 1982, e representados pelo conjunto de Equações (3), para horizontes de 12 horas a 48 horas respectivamente:

$$
\begin{aligned}
& \hat{\mathrm{Q}}_{\mathrm{UV}_{\mathrm{t}+1}}=1,42 \mathrm{Q}_{\mathrm{UV}_{\mathrm{t}}}-0,25 \mathrm{Q}_{\mathrm{UV}_{\mathrm{t}-1}}-0,17 \mathrm{Q}_{\mathrm{UV}_{\mathrm{t}-2}} \\
& \hat{\mathrm{Q}}_{\mathrm{UV}_{\mathrm{t}+2}}=1,76 \mathrm{Q}_{\mathrm{UV}_{\mathrm{t}}}-0,53 \mathrm{Q}_{\mathrm{UV}_{\mathrm{t}-1}}-0,24 \mathrm{Q}_{\mathrm{UV}_{\mathrm{t}-2}} \\
& \hat{\mathrm{Q}}_{\mathrm{UV}_{\mathrm{t}+3}}=1,97 \mathrm{Q}_{\mathrm{UV}_{\mathrm{t}}}-0,68 \mathrm{Q}_{\mathrm{UV}_{\mathrm{t}-1}}-0,29 \mathrm{Q}_{\mathrm{UV}_{\mathrm{t}-2}} \\
& \hat{\mathrm{Q}}_{\mathrm{UV}_{\mathrm{t}+4}}=2,12 \mathrm{Q}_{\mathrm{UV}_{\mathrm{t}}}-0,79 \mathrm{Q}_{\mathrm{UV}_{\mathrm{t}-1}}-0,32 \mathrm{Q}_{\mathrm{UV}_{\mathrm{t}-2}}
\end{aligned}
$$

onde: $\hat{Q}_{\mathrm{UV}_{\mathrm{t}+1}}$ é a previsão em União da Vitória para 12 horas à frente e $\mathrm{Q}_{\mathrm{UV}_{\mathrm{t}}}$ é a vazão observada em União da Vitória no instante de tempo t.

$\mathrm{Na}$ época, a autora utilizou para verificação do resultado apresentado pelos modelos (3), as cheias ocorridas em janeiro de 1971, julho de 1978, janeiro de 1981 e julho de 1983. A Tabela 2 apresenta a qualidade das previsões em termos do coeficiente de correlação $(\rho)$ e do erro padrão da estimativa $\left(\mathrm{m}^{3} \mathrm{~s}^{-1}\right)$, este último calculado tanto para os hidrogramas completos $\left(\sigma_{1}\right)$ como considerando apenas o trecho de ascensão $\left(\sigma_{2}\right)$.

Percebe-se que o erro padrão é maior na subida dos hidrogramas, devido ao fato das previsões feitas com modelos ARIMA estarem sempre um pouco atrasadas, uma vez que esses modelos utilizam informações passadas no próprio local de interesse. Por outro lado, para o trecho do rio Iguaçu em União da Vitória, cujos hidrogramas têm uma variabilidade temporal muito lenta, este erro é admissível. Evidentemente, a qualidade das previsões decresce
Tabela 2. Verificação do ajuste do modelo ARIMA $(2,1,0)$.

\begin{tabular}{cccccc}
\hline \multirow{2}{*}{ Ano } & Est. & \multicolumn{4}{c}{ Horizonte de previsão (h) } \\
& & 12 & 24 & 36 & 48 \\
\hline \multirow{2}{*}{1971} & $\sigma_{1}$ & 35,71 & 61,16 & 99,05 & 128,65 \\
& $\sigma_{2}$ & 40,38 & 72,19 & 115,91 & 159,03 \\
& $\rho$ & 0,9989 & 0,9980 & 0,9941 & 0,9903 \\
\hline \multirow{2}{*}{1978} & $\sigma_{1}$ & 21,60 & 38,80 & 63,30 & 87,50 \\
& $\sigma_{2}$ & 29,80 & 54,40 & 84,90 & 114,40 \\
& $\rho$ & 0,9958 & 0,9865 & 0,9640 & 0,9320 \\
\hline \multirow{2}{*}{1981} & $\sigma_{1}$ & 53,54 & 104,30 & 165,90 & 226,70 \\
& $\sigma_{2}$ & 103,06 & 205,70 & 329,10 & 453,50 \\
& $\rho$ & 0,9930 & 0,9733 & 0,9295 & 0,8646 \\
\hline \multirow{2}{*}{1983} & $\sigma_{1}$ & 115,07 & 235,04 & 370,26 & 510,36 \\
& $\sigma_{2}$ & 236,11 & 492,99 & 779,78 & 1058,3 \\
& $\rho$ & 0,9930 & 0,9760 & 0,9430 & 0,8980 \\
\hline
\end{tabular}

com o aumento do alcance para o qual são realizadas, fato este refletido no decaimento do coeficiente de correlação.

O intervalo de discretização das vazões em União da Vitória é de aproximadamente 12 horas, uma vez que as observações usadas para o ajuste do modelo foram realizadas duas vezes por dia, às 7:00 h e às 17:00 h. Como os modelos ARIMA trabalham com intervalos discretos de tempo e eqüidistantes, considerou-se, para efeito deste estudo, que as vazões em União da Vitória correspondem às 6:00 h e às 18:00 h respectivamente, adiantando-se e atrasando-se em apenas uma hora o tempo da observação. Tendo em vista que nunca se tem certeza da hora exata em que o observador faz a leitura da régua e devido ao pequeno intervalo de tempo, esta simplificação não resulta em erro significativo que não possa ser aceito.

O modelo ARIMA $(2,1,0)$ foi aplicado para as sete cheias aqui estudadas e para os quatro horizontes de previsão. Para se obter as previsões para horizontes de tempo de $1 \mathrm{~h}$ até $11 \mathrm{~h}$ à frente, as vazões foram interpoladas usando-se uma função spline cúbica. Os modelos não foram reestimados usando-se informações horárias, uma vez que estas também foram obtidas em União da Vitória por interpolação, e provavelmente o ganho seria muito pequeno. Caso se dispusesse de observações horárias de níveis em União da Vitória, esse ganho poderia ter sido avaliado e o estado do sistema atualizado em tempo real para esta seção. Por outro lado, devido às características da bacia a montante de União da Vitória, a variação temporal da vazões para um intervalo de tempo horário é muito pequena, dispensando este refinamento, que já não pode deixar de ser levado em conta na bacia incremental entre União da Vitória e Foz do Areia.

Apesar do modelo acima ter sido estimado com base em enchentes ocorridas no período 1939-1982, apresentou-se eficiente para as previsões posteriores a este período, como pode ser evidenciado pelos gráficos apresentados 
na Figura 6. Discussões mais detalhadas da aplicação do modelo ARIMA $(2,1,0)$ em União da Vitória o leitor encontrará em Mine (1984) e Mine (1986).

\section{Previsão de vazões entre União da Vitória e Foz do Areia}

A previsão deste trecho envolveu o seguinte:

- Ajuste do modelo IPH II: a fase de ajuste do modelo para a bacia em questão o leitor poderá encontrar em Mine (1998) e Mine e Tucci (1999);

- Previsão da precipitação;

- Previsão com o modelo ajustado.

A Figura 7 apresenta todas as estações hidrométricas utilizadas neste trecho da bacia hidrográfica.

Previsão da precipitação - As seguintes opções para a previsão de chuvas foram consideradas: a) a chuva futura é conhecida dentro do horizonte de previsão, ou seja, feita igual à chuva observada; b) a chuva cessa durante o horizonte de previsão; c) a chuva futura é dada pelo modelo estocástico.

Para atender a terceira opção acima mencionada foi utilizado um modelo estocástico (ARIMA) para previsão de chuvas, que apesar de prático do ponto de vista operacional, nem sempre produz previsões adequadas.

A estimativa dos parâmetros de um modelo ARMA para precipitações horárias é muito mais complexa do que quando se trabalha com dados em uma escala de tempo maior, como dados mensais, por exemplo. A principal razão é o caráter intermitente da chuva horária e o grande número de zeros da série, correspondentes aos dias sem chuva, o que a torna fortemente não estacionária.

Burlando et al. (1993), ajustando modelos ARMA para chuvas horárias, obtiveram resultados melhores usando a chuva média na bacia do que estimando o modelo para cada local de estação pluviométrica e depois compondo a chuva média.

Este foi o procedimento adotado neste trabalho, onde a chuva considerada para efeito de estimar o modelo de previsão foi a média na bacia, calculada pelo método de Thiessen com os pluviômetros localizados próximos das recentes estações automáticas instaladas (ver Figura 7).

A equação para o cálculo da chuva média entre União da Vitória e Foz do Areia é:

$$
\overline{\mathrm{P}}=0,1642 \mathrm{P}_{\mathrm{UV}}+0,2639 \mathrm{P}_{\mathrm{JG}}+0,3810 \mathrm{P}_{\mathrm{MG}}
$$

onde: $\overline{\mathrm{P}}$ - precipitação média na bacia; $\mathrm{P}_{\mathrm{UV}}$ - precipitação em União da Vitória; $P_{J G}$ - precipitação em Jangada; $P_{M G}$ precipitação em Madeireira Gavazzoni; PUB - precipitação em Usina Bituruna (próxima ao local da barragem).

Adotaram-se dois tipos de séries para a estimativa dos parâmetros, buscando aquela que fornecesse a melhor

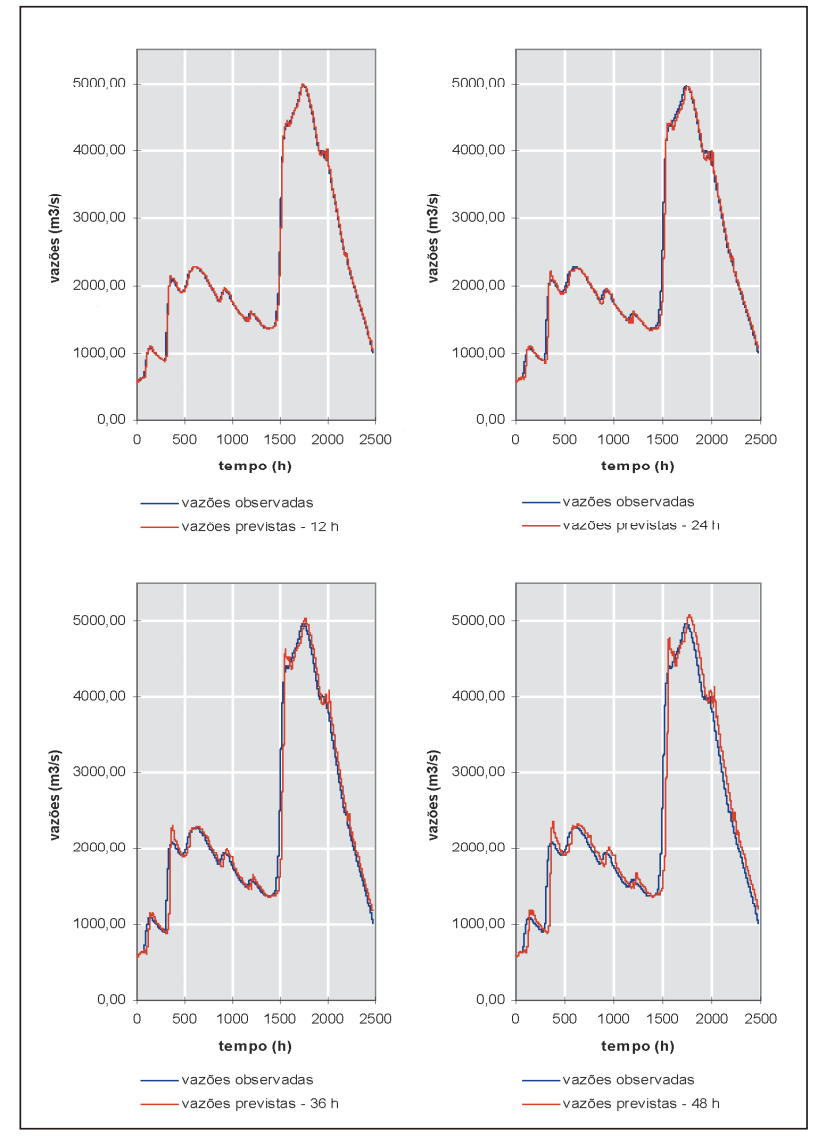

Figura 6. Vazões observadas e previstas - União da Vitória - 1983.

previsão: a) série transformada Box-Cox de primeira ordem; b) série original.

Como a Equação (1) é válida para processos estacionários, com distribuição marginal normal, submeteu-se a série original a uma transformação Box-Cox de primeira ordem, com o objetivo de obter dados normalmente distribuídos. As equações da transformação são:

$$
\begin{array}{ll}
z=\left(y^{\lambda}-1\right) / \lambda & \lambda \neq 0 \\
z=\log y & \lambda=0
\end{array}
$$

onde: $\mathrm{z}$ - série transformada; $\mathrm{y}$ - série original; $\lambda$ - parâmetro da transformação.

O maior inconveniente destes modelos foi não terem sido capazes de prever as chuvas para horizontes superiores a $1 \mathrm{~h}$, uma vez que ocorriam valores previstos da série transformada Box-Cox superiores a $-1 / \lambda$, inviabilizando a passagem para a série original, sempre que $\lambda_{z}+1<0$. É provável que isto tenha ocorrido porque a transformação Box-Cox não é apropriada para chuvas horárias. Note-se 
que, devido ao grande número de dias sem chuva, a distribuição de probabilidades acaba sendo truncada em $-1 / \lambda$, mesmo para séries de eventos pluviais, e o ajuste das variáveis transformadas à distribuição normal não satisfaz os testes de aderência comumente utilizados. Logo, deixa-se como recomendação para estudos futuros, buscar transformações mais adequadas para o caso.
Devido aos resultados, utilizou-se uma abordagem mais simplificada, agora com o único intuito de ter algum modelo de previsão de chuvas que mostrasse, apesar de todas as incertezas e inadequações aqui aceitas, que há uma grande necessidade por parte da comunidade científica meteorológica de investir em pesquisas para obtenção de boas previsões quantitativas de chuva, quer de curto ou longo

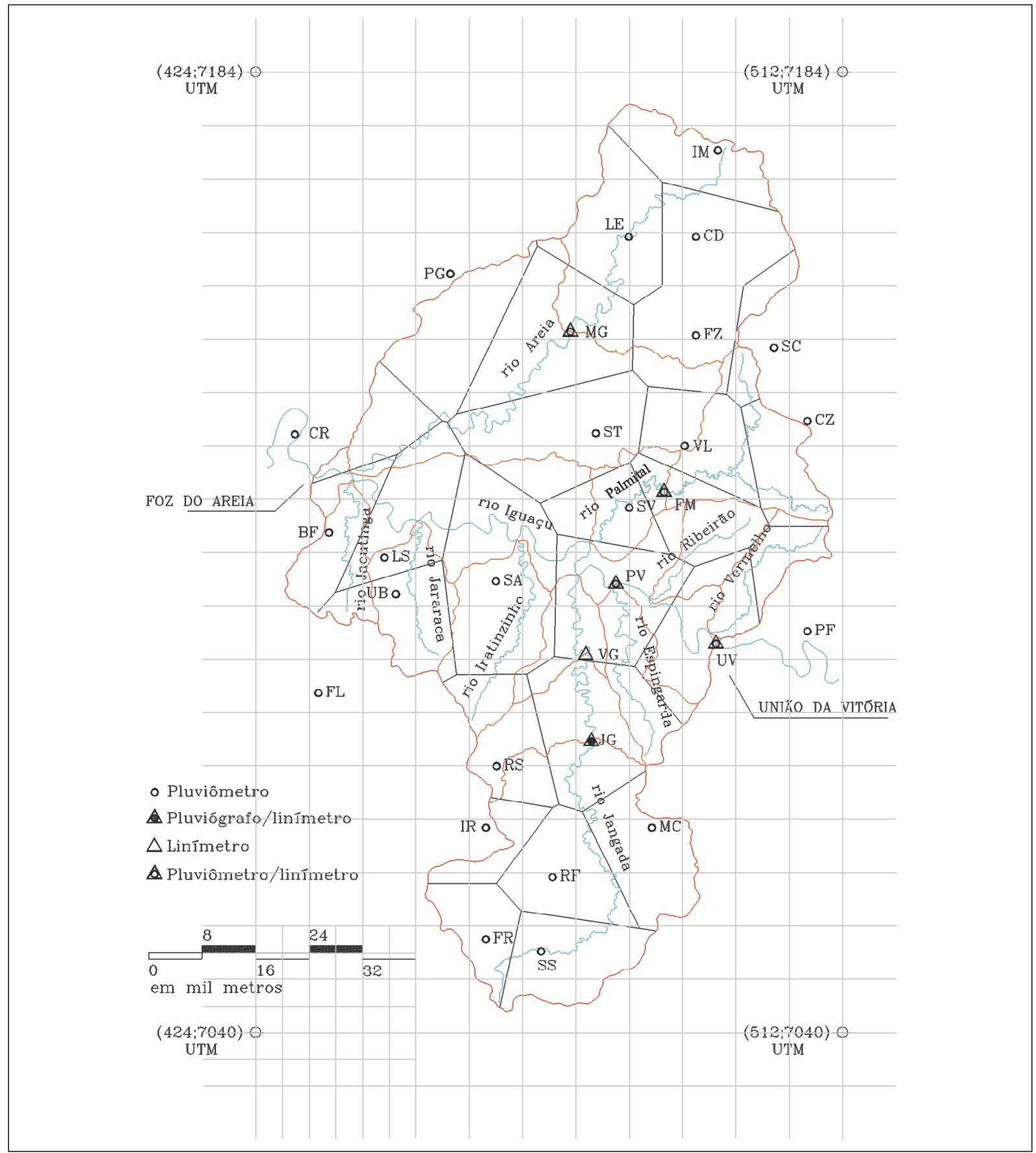

Figura 7. Estações hidrométricas utilizadas no estudo. 
termos, para que se possa operar com maior eficiência os reservatórios de geração hidrelétrica.

Partindo-se agora da série original de chuvas horárias, identificou-se pelo procedimento estabelecido por Box \& Jenkins (1976), um modelo ARMA (1,1). As funções de autocorrelação (FAC) e autocorrelação parcial (FACP) amostrais apresentaram-se muito próximas das respectivas funções teóricas, ambas com decaimento exponencial e válidas para a região de parâmetros auto-regressivos e de médias móveis positivos.

Os valores obtidos para os parâmetros auto-regressivo e de médias móveis são respectivamente iguais a 0,82683 e 0,49858 . A média e variância residuais são respectivamente iguais a $0,2 \mathrm{mmh}^{-1}$ e $2,4 \mathrm{mmh}^{-1}$. Como era esperado, o valor da estatística de Portmantean $(\mathrm{Q}=102)$ apresentou um valor alto quando comparado ao quiquadrado $\left(\chi_{0,05 ; 18}^{2}=28,9\right)$.

A seguir apresenta-se a equação do modelo para diversos horizontes de previsão:

\section{- 1 hora}

$$
\hat{\mathrm{y}}_{\mathrm{t}+1}=\phi_{1} \mathrm{y}_{\mathrm{t}}-\theta_{1} \mathrm{a}_{\mathrm{t}}
$$

onde: $a_{t}=z_{t}-\hat{z}_{t} ; \hat{y}_{t+1}$ - chuva prevista para um intervalo de tempo a frente; $\mathrm{y}_{\mathrm{t}}$ - chuva observada no instante de tempo t; $a_{t}$ - ruídos; $\phi_{1}$ - parâmetro autoregressivo; $\theta_{1}$ - parâmetro de médias-móveis.

- 2 horas

$$
\hat{\mathrm{y}}_{\mathrm{t}+2}=\phi_{1}^{2} \mathrm{y}_{\mathrm{t}}-\phi_{1} \theta_{1} \mathrm{a}_{\mathrm{t}}
$$

\section{- 3 horas}

$$
\hat{\mathrm{y}}_{\mathrm{t}+3}=\phi_{1}^{3} \mathrm{y}_{\mathrm{t}}-\phi_{1}^{2} \theta_{1} \mathrm{a}_{\mathrm{t}}
$$

Generalizando as equações acima para um horizonte de previsão $\ell$ horas, vem:

$$
\hat{y}_{\mathrm{t}+\ell}=\phi_{1}^{\ell} \mathrm{y}_{\mathrm{t}}-\phi_{1}^{\ell-1} \theta_{1} \mathrm{a}_{\mathrm{t}}
$$

Escrevendo a equação geral com os parâmetros estimados, resulta:

$$
\hat{y}_{\mathrm{t}+\ell}=(0,82683)^{\ell} \mathrm{y}_{\mathrm{t}}-(0,82683)^{\ell-1}(0,49858) \mathrm{a}_{\mathrm{t}}
$$

O modelo dado pela Equação (10) foi aplicado para $\ell=1,2, \ldots, 12$, conforme ilustrado na Figura 8 para o evento de 1983. Observou-se que as previsões para $\ell=1$ são semelhantes às obtidas com o modelo $\operatorname{ARMA}(2,2)$ estimado usando-se a transformada Box-Cox. É claro que estas
Tabela 3. Características físicas das sub-bacias.

\begin{tabular}{lcrcc}
\hline Rio & $\mathrm{A}\left(\mathrm{km}^{2}\right)$ & $\mathrm{L}(\mathrm{km})$ & $\mathrm{H}(\mathrm{m})$ & $\mathrm{S}(\mathrm{m} \mathrm{10000-1})$ \\
\hline Areia & 2094,69 & 138,03 & 601,00 & 43,54 \\
Areia-MG & 972,8 & 65,70 & 391,00 & 59,51 \\
Palmital & 475,7 & 85,71 & 489,00 & 57,05 \\
Palmital-FM & 328,5 & 53,23 & 349,00 & 65,56 \\
Ribeirão & 154,2 & 23,14 & 360,00 & 155,57 \\
Espingarda & 174,6 & 42,75 & 300,00 & 70,17 \\
Vermelho & 151,8 & 34,55 & 400,00 & 115,77 \\
Jangada & 1402,9 & 134,24 & 600,00 & 44,70 \\
Jangada-JG & 1047,3 & 82,38 & 450,00 & 54,62 \\
Iratinzinho & 248,5 & 44,78 & 420,00 & 93,79 \\
Jararaca & 204,4 & 31,43 & 420,00 & 133,63 \\
Jacutinga & 170,6 & 29,42 & 410,00 & 139,36 \\
\hline
\end{tabular}

$\mathrm{A}=$ área; $\mathrm{L}=$ comprimento do talvegue;

$\mathrm{H}=$ desnível; $\mathrm{S}=$ declividade.

previsões, já não sendo boas para $\ell=1$, tornam-se cada vez piores com o aumento deste alcance de previsão.

Previsão com modelo hidrológico - O modelo hidrológico foi ajustado e verificado para as bacias intermediárias ao reservatório e descrito em Mine e Tucci (1999).

A previsão da afluência foi realizada com o modelo ajustado para vários eventos. A área total da bacia hidrográfica neste trecho é de $5874,7 \mathrm{~km}^{2}$ e o modelo IPH II para determinação da contribuição lateral pôde ser calibrado em $42,8 \%$ da área. Os restantes $57,2 \%$ da contribuição lateral foi estimada aplicando-se o modelo IPH II com parâmetros adotados em função da área de drenagem e através de equações definidas com os parâmetros obtidos durante a fase de ajuste. A porcentagem da área tratada como concentrada foi de 86,4\% restando apenas 13,6\% para ser tratada de forma distribuída em dois trechos do rio Iguaçu, o primeiro compreendido entre União da Vitória e a confluência com o rio Jangada, e o segundo, desta seção com a barragem de Foz do Areia. Não houve, portanto, necessidade de propagação em canal nos afluentes. A Tabela 3 resume as diversas sub-bacias e respectivas áreas de drenagem usadas na estimativa da contribuição lateral.

Precipitação: A chuva média em todas as sub-bacias foi calculada pelo método de Thiessen (ver Figura 7).

Condições iniciais As condições de escoamentos subterrâneo $\mathrm{Q}_{\text {sub }}$ e superficial $\mathrm{Q}_{\text {sup }}$ foram estabelecidas por relação de áreas com as sub-bacias vizinhas em que o modelo IPH II pôde ser calibrado e a percolação $T_{0}$ foi feita igual ao escoamento subterrâneo no início da simulação. $O$ estado inicial do reservatório de perdas $\mathrm{R}$ (em $\mathrm{mm}$ ) foi estimado em $30 \%$ de $R_{\max }$.

Parâmetros do modelo: Os parâmetros de infiltração foram obtidos com base na semelhança das características das bacias com dados e sem dados observados.

Para todas as sub-bacias o tempo de percurso da onda de cheia foi feito igual ao tempo de concentração $\left(t_{p}=t_{c}\right)$ estimado pela fórmula de Dooge (Mine, 1998), por 
apresentar valores menores para $t_{c}$, tendo em vista a resposta rápida das sub-bacias em questão. Para as sub-bacias distribuídas, adotou-se $t_{\mathrm{p}}=2 \mathrm{~h}$.

O parâmetro $K_{\text {sup }}$ representa o tempo de retardo do escoamento superficial, ou seja, é o tempo (em número de intervalos), contado entre o centro de massa do hietograma (após a aplicação do HTA) e o centro de massa do hidrograma. Este parâmetro depende de características físicas da bacia hidrográfica e também do armazenamento bacia hidrográfica e também do armazenamento e da celeridade da onda. Para as sub-bacias sem dados utilizou-se as informações das características físicas das bacias com dados e sem dados para extrapolar os valores para as bacias sem dados.

O parâmetro $K_{\text {sub }}$ é pouco sensível na simulação de enchentes. Este parâmetro representa o tempo de retardo do escoamento subterrâneo e foi determinado com base na

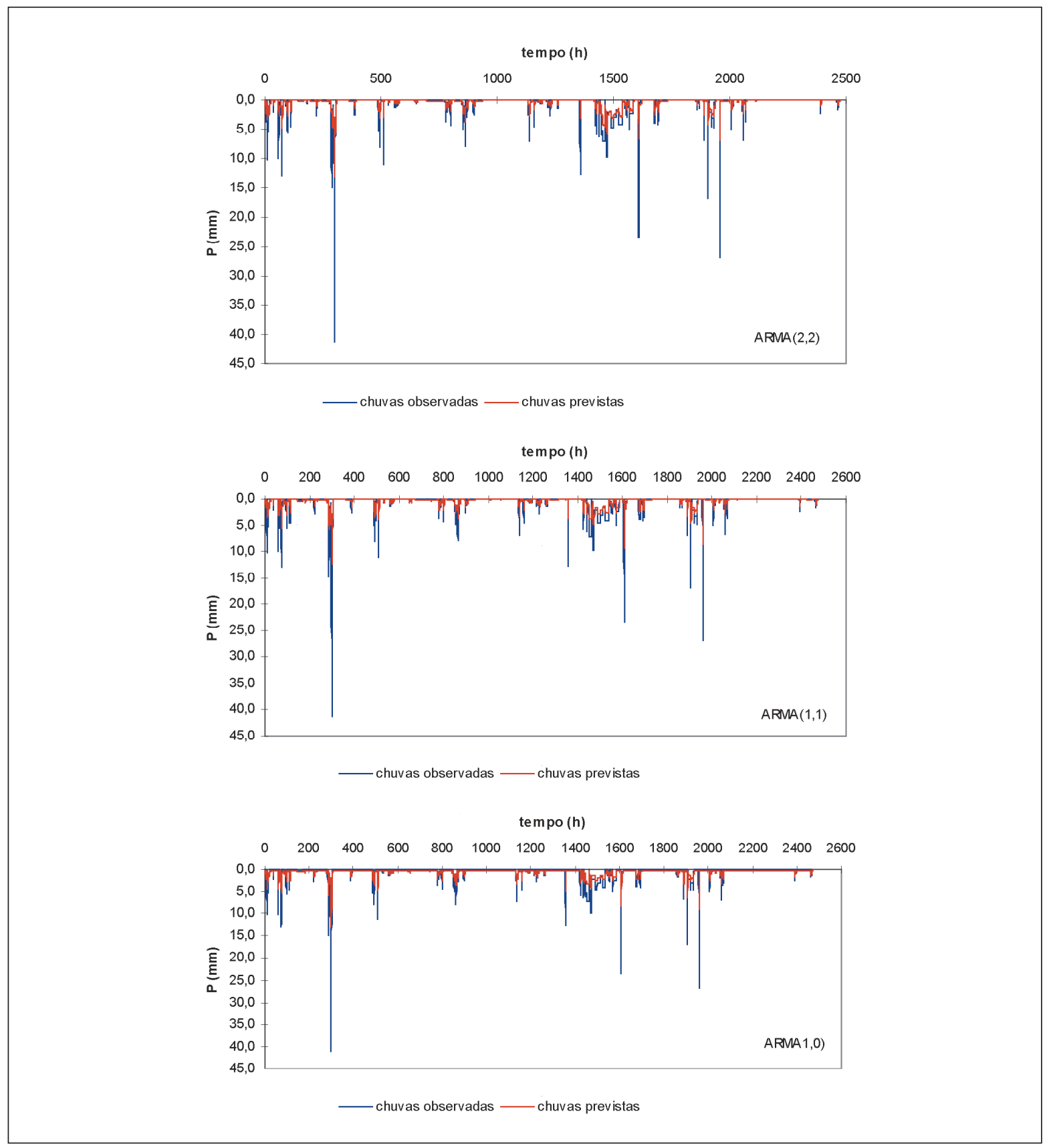

Figura 8. Previsões de chuva - ARMA (1,1) - HP = 1 h a 4 h - evento de 1983. 
recessão dos hidrogramas estudados, sendo $K_{\text {sub }}=1 / \alpha$ onde: $\alpha=-\ln \left(\mathrm{Q}_{\mathrm{t}} / \mathrm{Q}_{\mathrm{t}-1}\right), \mathrm{Q}_{\mathrm{t}}$ - vazão no instante $\mathrm{t}$, no trecho de recessão do hidrograma.

O parâmetro $R_{\max }$ representa o volume do reservatório de perdas iniciais, e para fins deste estudo, adotou-se um valor médio, calculado em função dos valores obtidos na fase de ajuste do modelo IPH II.

Como a resposta das sub-bacias entre União da Vitória e Foz do Areia é muito rápida e a propagação das vazões de União da Vitória é praticamente instantânea, foi possível comparar o hidrograma de contribuição lateral observado, obtido pela soma das vazões nas quatro sub-bacias onde são feitas leituras de régua, com o bidrograma de contribuição lateral simulado para estes mesmos locais de observação (Figura 9), e ainda com a contribuição lateral total, obtida pela soma das vazões resultantes da aplicação do modelo IPH II para todas as sub-bacias concentradas e distribuídas. Esta contribuição lateral total foi somada às vazões observadas em União da Vitória e comparada com as vazões em Foz do Areia, permitindo verificar o comportamento da contribuição lateral em termos de volume, pico e tempo de pico, tendo-se obtido bons resultados para os eventos de 1982, 1983 e 1992. A Figura 10 ilustra esses hidrogramas para a cheia de 1982 .

\section{Simulação da operação}

A operação normal, para controle de cheias em um reservatório, é aquela durante a qual a situação permanece sob o controle do Centro de Operação da empresa responsável, não havendo perspectivas de esgotamento dos volumes de espera alocados para atender as restrições consideradas, nem a necessidade de liberação de descargas defluentes superiores às respectivas descargas de restrição. No caso de Foz do Areia, pelo fato de sua restrição estar a montante, o nível do volume de espera recomendado corresponde a um nível meta que poderá ser rebaixado de forma dinâmica, tendo em vista uma proteção adicional para as cidades localizadas a montante (GCOI, 1991). Historicamente, o nível do volume de espera tem variado entre $741,5 \mathrm{~m}$ e $742,0 \mathrm{~m}$, coincidindo neste último caso, com o nível máximo normal de operação.

Previsão na operação - Para a aplicação do modelo de previsão de afluências e simulação da operação do reservatório utilizou-se o seguinte:

1. O módulo bacia do modelo IPH IV foi adaptado do modo simulação hidrológica para o modo previsão hidrológica e simulação da operação. Evidentemente, em outras aplicações do método proposto, em que haja necessidade de propagação em canal, todo o programa IPH IV (módulos bacia e canal) deverá ser adaptado para o modo previsão e simulação da operação. Neste estudo de caso, o modelo IPH IV completo foi usado para verificar se a restrição de montante não era violada, com a regra operacional definida.

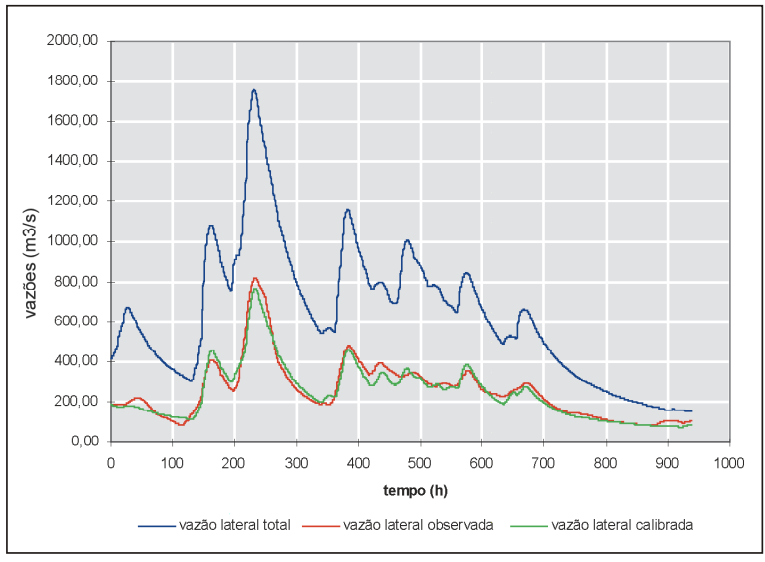

Figura 9. Comparação entre contribuição lateral ajustada e simulada - 1982.

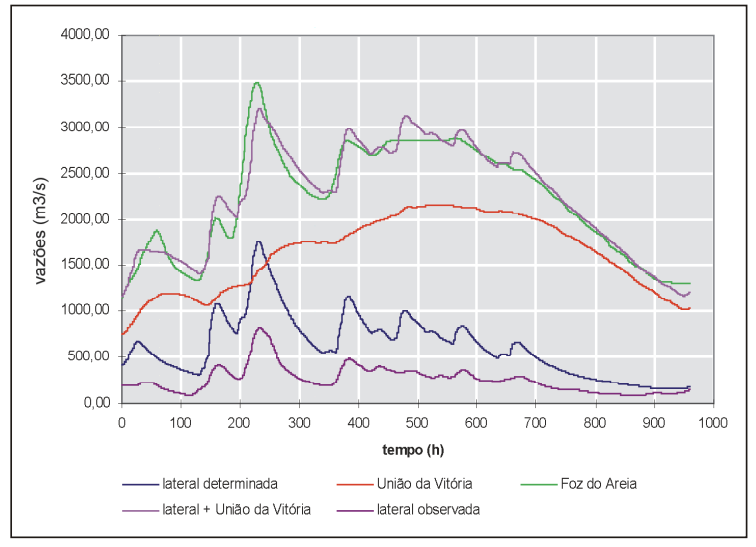

Figura 10. Verificação da qualidade da contribuição lateral total -1982 .

2. Para iniciar a simulação, é suficiente ter informações passadas armazenadas, correspondentes a um tempo pouco maior que o de concentração da bacia a montante de Foz do Areia (aproximadamente 24 horas, mais as informações correspondentes a um período de inicialização do modelo, totalizando aproximadamente 10 dias de informações horárias).

3. Os arquivos de dados dos programas são atualizados em tempo real a cada hora (ou a cada quatro horas com discretização horária) em que se recebem informações pluviométricas.

4. Faz-se uma previsão em União da Vitória para um tempo $t+\tau$, com o modelo ARIMA $(2,1,0)$.

5. Os arquivos de dados do programa IPH IV devem ser completados com as previsões de vazões em União da Vitória e previsões de chuvas na bacia incremental até o tempo $t+\tau$.

6. Inicia-se a simulação no instante de tempo to quando as condições meteorológicas indicarem períodos chuvosos, que no Sul do Brasil tanto podem ocorrer no verão como no inverno. 
7. O modelo é executado a cada HD horas (horizonte de decisão, determinado pelo Centro de Operação do Sistema - COS), disponibilizando previsões para todos os instantes de tempo $t, t+1, t+2, t+3, \ldots, t+t_{f}$, sendo $t_{f} \mathrm{o}$ fim do período chuvoso. $\mathrm{O}$ modelo também poderá ser executado apenas quando o COS achar conveniente, lembrando-se, no entanto, que os arquivos de dados devem estar atualizados até o tempo em que se faz a previsão.

8. O estado do sistema, na bacia intermediária, é atualizado à medida que novas informações tornam-se disponíveis.

Restrições operacionais - As restrições operativas compreendem o conjunto de limitações a seguir: i) níveis no reservatório que não causem prejuízos, a montante, devido ao remanso; ii) máximas descargas que podem ser liberadas sem causar danos à jusante; iii) taxas de máxima variação de defluência durante a operação normal.

Essas taxas são as variações máximas de defluência a serem respeitadas no intervalo de decisão, de forma a evitar oscilações bruscas. No caso de Foz do Areia, a taxa máxima a ser adotada é obtida multiplicando-se o valor horário da taxa pelo número de horas decorridos desde a última tomada de decisão (manobra de comporta). As taxas apresentadas a seguir são consideradas referenciais, devido ao histórico de vazões naturais afluentes (Cunha, 1995).

O tempo médio, necessário para manobra de comportas, é em torno de cinco minutos, portanto, muito pequeno, não sendo necessário considerá-lo na avaliação do volume a ser vertido (Cunha, 1997).

A seguir são apresentadas as restrições físicas e operacionais do reservatório de Foz do Areia (Cunha, 1995):

$\mathrm{Z}_{\min } \leq \mathrm{Z}(\mathrm{t}) \leq \mathrm{Z}_{\max }$

$Z_{\min }=700,00 \mathrm{~m}$ correspondente ao nível mínimo operativo;

$\mathrm{Z}_{\max }=742,00 \mathrm{~m}$ correspondente ao nível máximo em operação normal;

$\mathrm{Z}_{\max }=745,00 \mathrm{~m}$ correspondente ao nível máximo maximorum (cota de desapropriação rural);

$\Delta \mathrm{Q}_{\mathrm{d}}=600 \mathrm{~m}^{3} \mathrm{~s}^{-1} \mathrm{~h}^{-1}$ correspondente à taxa de máxima variação de defluência horária quando $\mathrm{Q}_{\mathrm{d}}<2000$ $\mathrm{m}^{3} \mathrm{~s}^{-1}$

$\Delta \mathrm{Q}_{\mathrm{d}}=1000 \mathrm{~m}^{3} \mathrm{~s}^{-1} \mathrm{~h}^{-1}$ correspondente à taxa de máxima variação de defluência horária quando $\mathrm{Q}_{\mathrm{d}}>$ $2000 \mathrm{~m}^{3} \mathrm{~s}^{-1}$.

A restrição de montante está condicionada às regiões do gráfico apresentado na Figura 11, de tal forma que o nível no reservatório não afogue o controle hidráulico de Porto Vitória.

Regra operacional - A regra operacional (nível máximo de operação na cota 742,0 m) para Foz do Areia foi definida em função: i) do estado do reservatório; ii) das previsões de afluências ao reservatório; iii) das previsões de va-

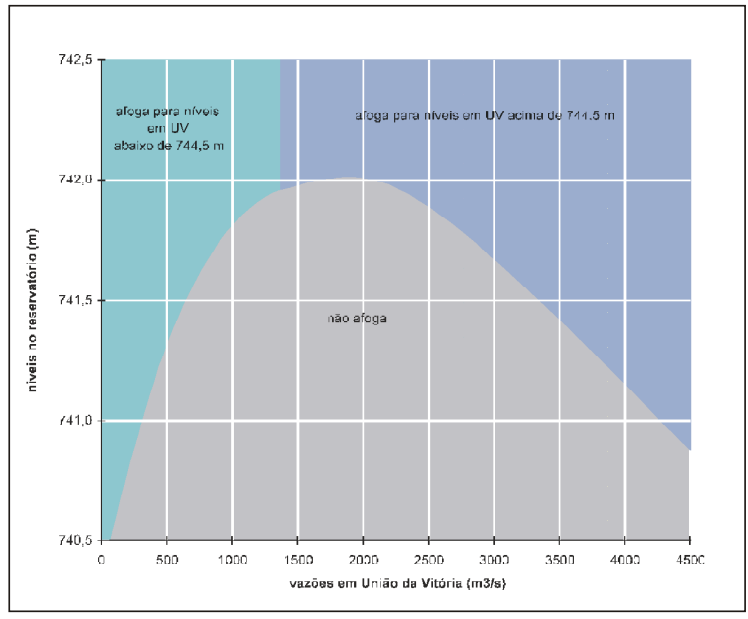

Figura 11. Condições hidráulicas do escoamento em Porto Vitória.

zões em União da Vitória; iv) das condições hidráulicas de escoamento no trecho União da Vitória - Foz do Areia.

O reservatório, projetado para operar na cota $744,0 \mathrm{~m}$, foi rebaixado para cota $742,0 \mathrm{~m}$ em função de conclusões de estudos anteriores, com a finalidade de atender a restrição de montante. Com este rebaixamento do nível máximo normal de operação, pode-se dizer que foi criado uma espécie de volume de espera permanente no reservatório, cujo nível ainda precisa ser rebaixado em tempo real, quando da ocorrência de eventos extremos. Este rebaixamento foi feito em função da previsão de afluências ao reservatório e de vazões em União da Vitória, através do modelo proposto neste estudo.

Para atender a restrição de montante e não deplecionar o reservatório muito abaixo da cota $742,0 \mathrm{~m}$, procurouse operá-lo de tal forma a evitar que o controle hidráulico, por vertedouro natural, situado em Porto Vitória, não fosse afogado, evitando, desta forma, que o remanso, provocado pelo reservatório, influenciasse os níveis em União da Vitória acima da cota de desapropriação urbana, que corresponde a 744,5 m (ver Figura 11).

A Tabela 4 apresenta o nível meta do volume de espera $\left(Z_{\mathrm{E}}\right.$ em $\left.\mathrm{m}\right)$ em função do estado do reservatório ( $\mathrm{Z}$ em $\mathrm{m}$ ) e das previsões de afluências em União da Vitória $\left(\hat{\mathrm{Q}}_{\mathrm{UV}} \mathrm{em} \mathrm{m}^{3} \mathrm{~s}^{-1}\right)$.

De acordo com o exposto acima definiu-se a seguinte regra de operação para o reservatório de Foz do Areia:

1. Com o modelo hidrológico (ARIMA e módulo bacia do IPH IV), faz-se uma previsão do volume afluente dentro do horizonte de previsão e estima-se o estado futuro do reservatório, pela soma do volume existente com o previsto.

2. Determina-se a capacidade de vertimento máximo em função da curva de descarga do vertedouro.

3. Calcula-se a defluência para condições limites, isto é, com o reservatório operando no nível máximo nor- 
mal, sem criar volume de espera adicional para controle de cheias.

4. Esta defluência é calculada pelo módulo da diferença, na unidade de tempo, do volume máximo normal e do volume estimado para o reservatório no fim do horizonte de previsão.

5. Se o volume estimado for menor ou igual ao volume máximo de operação, enche-se o reservatório ou mantém-se o nível durante o horizonte de previsão, defluindo a vazão correspondente às condições limites, desde que atendidas as restrições de defluência mínima (turbinamento previsto) e verificadas as máximas taxas de defluências horárias, apresentadas anteriormente, e função do horizonte de decisão.

6. No caso do volume estimado ser maior que o volume máximo de operação, o reservatório é deplecionado com a vazão defluente das condições limites até que, o nível em União da Vitória atinja a cota de alerta $(743,8 \mathrm{~m})$ e desde que sejam cumpridas as restrições de defluência mínima (turbinamento) e máximas variações de defluências horárias.

7. Quando o nível em União da Vitória atinge a cota de alerta, rebaixa-se o reservatório de tal forma a alocar um volume para o controle de cheias, dito volume de espera em tempo real, uma vez que é determinado à medida que o evento está ocorrendo, em função das previsões de afluências.

8. Este rebaixamento do reservatório deve respeitar as condições hidráulicas do escoamento no rio, que estão sumariadas na Figura 11, onde percebe-se que o reservatório só poderá operar na cota $742,0 \mathrm{~m}$ para vazões inferiores a $2720 \mathrm{~m}^{3} \mathrm{~s}^{-1}$ em União da Vitória, caso contrário, o nível de água no reservatório estará afogando o controle hidráulico de Porto Vitória e violando a restrição de montante.

9. Para levar em conta a situação acima, considera-se que o reservatório poderá encontrar-se, no fim do horizonte de previsão, em quatro possíveis estados:

- acima do nivel 742,0 m - nesta situação depleciona-se o reservatório da vazão defluente correspondente às condições limites, acrescida da diferença entre o volume correspondente ao volume estimado e o volume máximo normal de operação na unidade de tempo, desde que atendidas as demais restrições relacionadas nos itens (10.), (11.) e (12.);

- igual on inferior a 742,0 m- rebaixa-se o reservatório dentro do horizonte de previsão até a cota $741,0 \mathrm{~m}$, desde que atendidas as restrições dos itens (10.), (11.) e (12.);

- igual ou inferior a $741,5 \mathrm{~m}$ - se as previsões de vazão em União da Vitória forem inferiores a $3300 \mathrm{~m}^{3} \mathrm{~s}^{-1}$ é suficiente defluir o reservatório da vazão correspondente às condições limites, caso contrário, rebaixa-se o reservatório dentro do horizonte de previsão até a cota $740,5 \mathrm{~m}$;

- igual ou inferior a $741,0 \mathrm{~m}$ - se as previsões de vazão em União da Vitória forem inferiores a $4272 \mathrm{~m}^{3} \mathrm{~s}^{-1}$
Tabela 4. Níveis meta do volume de espera.

\begin{tabular}{ccc}
\hline$Z(\mathrm{~m})$ & $\hat{\mathrm{Q}}_{\mathrm{UV}}\left(\mathrm{m}^{3} \mathrm{~s}^{-1}\right)$ & $\mathrm{Z}_{\mathrm{E}}(\mathrm{m})$ \\
\hline $\mathrm{Z}>742,0$ & $\hat{\mathrm{Q}}_{\mathrm{UV}}<1400,0$ & $\mathrm{Z}_{\mathrm{E}}=742,0$ \\
$742,0 \geq Z>741,5$ & $1400,0 \leq \hat{\mathrm{Q}}_{\mathrm{UV}}<3300,0$ & $\mathrm{Z}_{\mathrm{E}}=741,0$ \\
$741,5 \geq Z>741,0$ & $\hat{\mathrm{Q}}_{\mathrm{UV}}<3300,0$ & 741,0 \\
& $\hat{\mathrm{Q}}_{\mathrm{UV}}>3300,0$ & 740,5 \\
$741,0 \geq Z>740,5$ & $\hat{\mathrm{Q}}_{\mathrm{UV}}<4272,0$ & 740,5 \\
& $\hat{\mathrm{Q}}_{\mathrm{UV}}>4272,0$ & 740,0 \\
\hline
\end{tabular}

é suficiente defluir o reservatório da vazão correspondente às condições limites, caso contrário, rebaixa-se o nível dentro do horizonte de previsão até a cota $740,0 \mathrm{~m}$, desde que verificados os itens (10.), (11.) e (12.);

10. Verificam-se as restrições quanto à defluência mínima, ou seja, vazões turbinadas previstas em função do despacho de carga.

11. Verificam-se restrições quanto à defluência máxima, função do vertimento máximo e turbinamento previstos.

12. Verificam-se as restrições quanto à máxima variação da defluênia horária permitida, função da magnitude da vazão defluente e do horizonte de decisão.

13. Recalculam-se volumes no reservatório e corrige-se o volume estimado para o próximo horizonte de previsão, em função do volume observado no último horizonte de decisão.

14. Atualizam-se as previsões a cada HD horas e reiniciase o procedimento em (1.) até o final do período chuvoso.

Resultados da simulação da operação - Foram realizadas simulações da operação do reservatório para horizontes de previsão (HP) de 12 h, 24 h, 36 h e 48 h e horizontes de decisão (HD) de $4 \mathrm{~h}$, com chuva conhecida e chuva zero, para todas as cheias estudadas. Com o objetivo de verificar o ganho com a redução do HD para $2 \mathrm{~h}$, foram feitas simulações para o HP de $24 \mathrm{~h}$. Para verificar a possibilidade de usar o modelo proposto somente com dados provenientes de apenas quatro estações automáticas de chuva, recentemente instaladas na bacia, simularam-se os níveis do reservatório para HP de 24 h e diferentes densidades pluviométricas (28 pluviômetros e quatro estações automáticas). Para verificação da influência do remanso em União da Vitória compararam-se os níveis simulados pelo modelo com a regra de operação real e com a operação proposta. Evidentemente, a comparação com valores observados seria distorcida pelo erro de ajuste do modelo. Todas as simulações foram feitas com o estado inicial do reservatório correspondente ao nível real, para que fosse possível comparar as duas regras operacionais. Apresenta-se, na seqüência, as principais conclusões das simulações, por evento: 
- Cheia de 1982:

i. os níveis operacionais no reservatório, obtidos da simulação com previsão de chuva conhecida e chuva zero foram aproximadamente iguais para o HP de $12 \mathrm{~h}$;

ii. os níveis operacionais obtidos da previsão com chuva zero e HP de $24 \mathrm{~h}$ foram praticamente os mesmos da simulação com chuva conhecida e HP de 36 h;

iii. os resultados obtidos com chuva zero e HP de $48 \mathrm{~h}$ foram melhores que a operação real, uma vez que esta operação influenciou os níveis em União da Vitória, conforme pode ser evidenciado pela Figura 12;

iv. apesar dos níveis reais terem se mantido acima dos níveis simulados durante o período chuvoso, a recuperação total do reservatório, no fim deste período, foi totalmente possível com o modelo proposto, como pode ser evidenciado pelas Figuras 12 e 13, sendo que esta última resume os resultados de todas as simulações com chuva zero e HD de 4 h;

v. a simulação feita para HP de $24 \mathrm{~h}$ e diferentes horizontes de decisão (HD de 2 h e 4 h) também resultou em níveis muito próximos;

vi. os níveis simulados com diferentes densidades de pluviômetros também foram praticamente os mesmos, tendo-se notado que os níveis simulados com 20 pluviômetros foram levemente mais altos.

- Cheia de 1983:

i. observa-se da Figura 13 que os níveis simulados para $\mathrm{HP}$ de $12 \mathrm{~h}$, tanto com chuva zero como com chuva conhecida foram praticamente os mesmos;

ii. houve violação da restrição de montante, com chuva zero, para o HP de $24 \mathrm{~h}$ durante um intervalo de aproximadamente quatro dias.

iii. apesar do nível máximo de operação ter sido violado, o nível simulado máximo do reservatório chegou a $742,71 \mathrm{~m}$, em contrapartida, a operação real elevou o nível a 743,58 m, correspondendo a uma diferença de $87 \mathrm{~cm}$ no nível do reservatório, que é significativa, quando resulta em um acréscimo de aproximadamente $9 \mathrm{~cm}$ no nível da enchente na cidade de União da Vitória;

iv. observa-se da Figura 14, que foi possível, mesmo simulando com chuva zero, antecipar o deplecionamento do reservatório e criar um volume de espera menor com relação à operação real, permitindo recuperá-lo totalmente no final do período chuvoso;

v. as simulações para HP superiores a $24 \mathrm{~h}$ e chuva zero, resultaram em níveis acima da cota $742,0 \mathrm{~m}$, influenciando os níveis em União da Vitória durante períodos mais longos de tempo;

vi. os níveis simulados com chuva zero e diferentes HD para HP de $24 \mathrm{~h}$ foram praticamente coincidentes;

vii. as mesmas conclusões obtidas para a cheia de 1982, simulando com 28 pluviômetros ou quatro pluviômetros, também foram muito semelhantes.

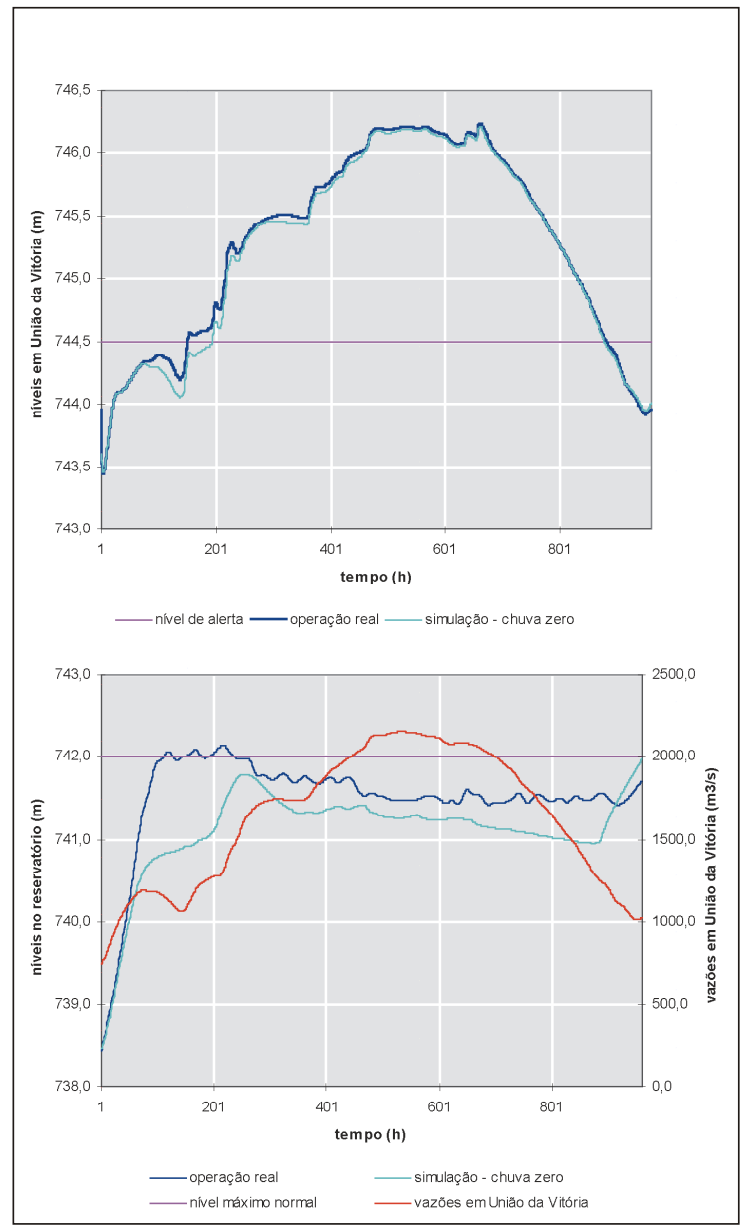

Figura 12. Simulação com chuva zero - HP $=48 \mathrm{~h}$ $\mathrm{HD}=4 \mathrm{~h}$ - evento de 1982

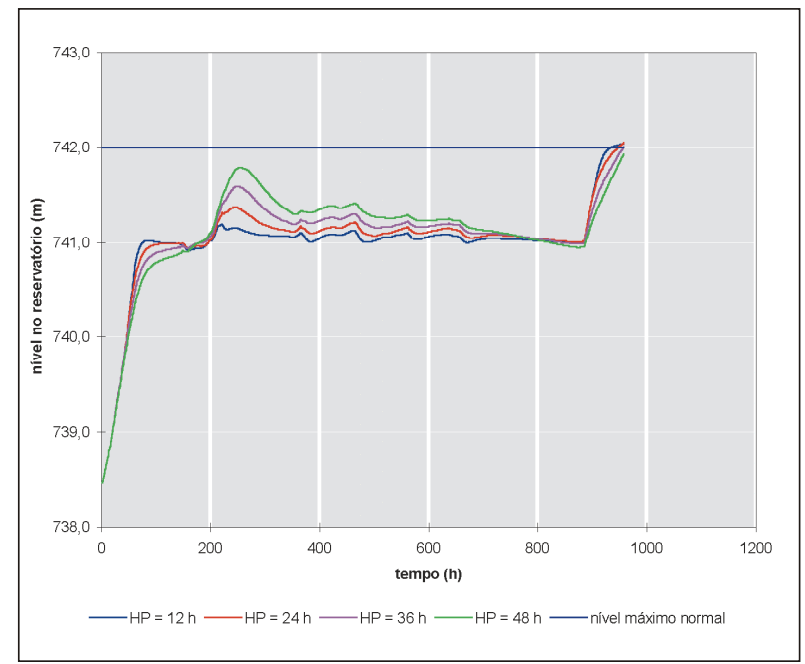

Figura 13. Níveis para diversos horizontes de previsão evento de 1982. 
- Cheia de 1987:

i. para esta cheia, os resultados da simulação da operação foram piores que da operação real para todas as situações, no sentido de que não foi possível recuperar totalmente o nível do reservatório, conforme apresentado na Figura 15, o que foi possível durante a operação real;

ii. note-se que essa cheia apresentou resultados insatisfatórios tanto em termos de simulação hidrológica quanto em termos de previsão de afluências;

iii. as conclusões quanto a diferentes $\mathrm{HD}$ e diferentes densidades de pluviômetros, permanecem as mesmas das cheias anteriores.

- Cheia de 1990:

i. conforme ocorreu nas cheias anteriores, os níveis do reservatório são muito próximos, quer sejam simulados com chuva conbecida ou chuva zero, para HP de $12 \mathrm{~h}$;

ii. a restrição de montante não foi violada em nenhuma das simulações realizadas, e foi possível operar o reservatório em níveis mais altos do que os observados.

- Cheia de 1992:

i. novamente, as mesmas conclusões das cheias anteriores se verificam quando a simulação é feita para HP de 12 horas e chuvas conbecida e zero;

ii. simulando o reservatório para HP de 24 h e chuva zero, não foi necessário deplecioná-lo para níveis inferiores a $734,5 \mathrm{~m}$ conforme ocorreu com a operação real (talvez este deplecionamento tenha sido por outro motivo que não controle de cheias!);

iii. observou-se, também, conforme ocorreu para a cheia de 1982, que os níveis foram aproximadamente os mesmos, quer a simulação tenha sido feita com chuva zero para HP de $24 \mathrm{~h}$ e chuva conbecida para HP de $36 \mathrm{~h}$;

iv. para horizontes de previsão superiores a $24 \mathrm{~h}$ e chuva zero, tal como ocorreu para a cheia de 1983, não foi possível criar um volume de espera capaz de amortecer a onda de cheia que não violasse as condições de níveis em União da Vitória;

v. as mesmas conclusões anteriores, quanto à densidade de pluviômetros e diferentes horizontes de decisão se verificaram para a cheia de 1992

- Cheias de 1993 e 1995 :

i. as mesmas conclusões das cheias anteriores se verificaram quando a simulação foi feita para HP de 12 horas e chuvas conhecida e zero, concluindo-se que este fato está associado ao tempo de resposta da bacia incremental entre União da Vitória e Foz do Areia, estimado em $12 \mathrm{~h}$;

ii. em todas as simulações com chuva zero foi possível manter o reservatório mais alto do que durante a $\mathrm{o}-$

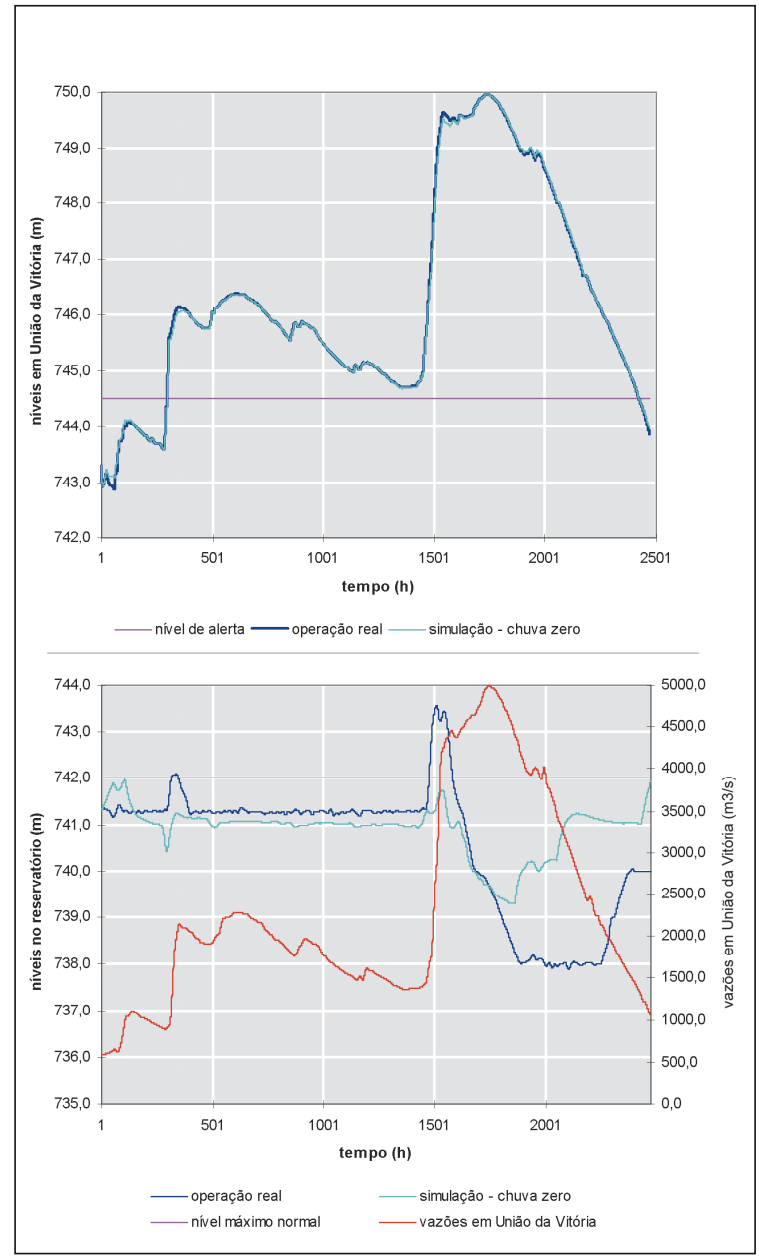

Figura 14. Simulação com chuva zero - HP $=12 \mathrm{~h}$ HD $=4 \mathrm{~h}$ - evento de 1983.

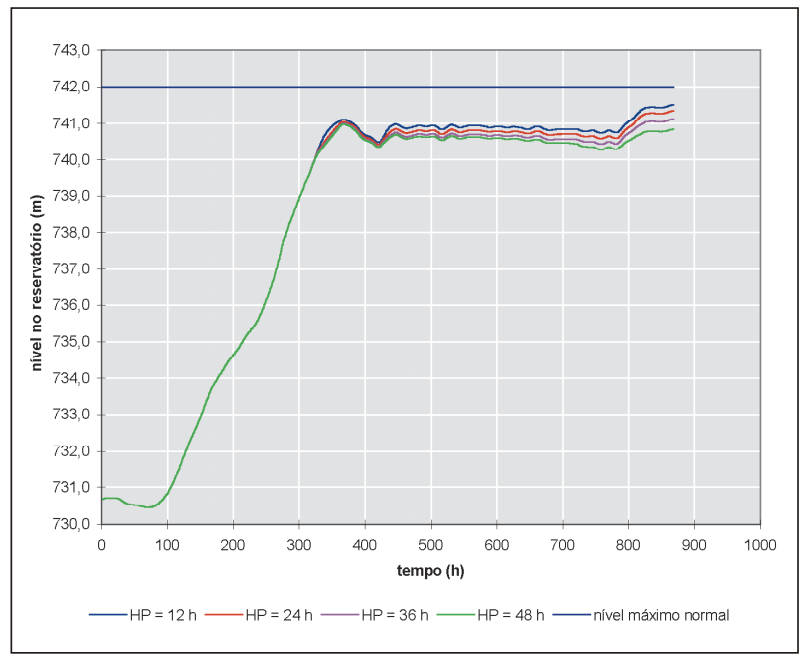

Figura 15. Níveis para diferentes horizontes de previsão evento de 1987. 
peração real, sem que houvesse necessidade de deplecioná-lo muito para ambas as cheias, de tal forma que foi possível recuperá-lo no fim do período chuvoso para a cheia de 1993.

Finalmente, para todos os casos, conclui-se que tanto faz operar o reservatório, calculando-se a chuva média na bacia com base em 28 pluviômetros (exceto quando há falhas) ou quatro estações pluviométricas, uma vez que os níveis operacionais não são sensíveis a estas diferentes densidades da rede de observações. É suficiente que as decisões sejam tomadas de $4 \mathrm{~h}$ em $4 \mathrm{~h}$ e que o estado do sistema também seja atualizado para este horizonte de decisão, não havendo necessidade de adotar horizontes menores.

\section{Risco da contribuição lateral romper a restrição} de montante - Uma preocupação com relação à operação do reservatório refere-se à importância da contribuição lateral na bacia intermediária. Apesar dessa contribuição ter pouca significância para alguns eventos, a região tem isoietas com precipitações mais intensas do que a montante de União da Vitória (Tucci e Villanueva, 1997). Devido à dificuldade em se obter previsões quantitativas de chuva de mesoescala, que possibilitem criar volumes de espera em tempo real de médio prazo, tanto a regra atualmente utilizada quanto a proposta neste trabalho adotam medidas operacionais depois do volume estar dentro do reservatório, isto é, quando a cota em União da Vitória atinge 4,19 m, criando-se, portanto, volumes de espera em tempo real, que podem ser entendidos como de curtíssimo prazo. Logo, em tese, condições desfavoráveis de nível alto no reservatório (acima da cota 741,5 m) juntamente com uma contribuição lateral significativa da bacia intermediária, poderiam agravar o nível de cheia em União da Vitória. Esta situação foi simulada para as duas maiores cheias ocorridas $(1983$; 1992) e o procedimento é descrito na seqüência.

Os sistemas frontais (frentes frias) foram responsáveis pelo grande volume precipitado em maio-junho-julho de 1983. Nesse período a atmosfera permaneceu muito instável, propiciando condições ideais para que sistemas frontais se desenvolvessem sobre o Paraná. Por outro lado, o El Niño estava em fase de desenvolvimento, dificultando a propagação das frentes sobre o Estado. Em julho (dias 6 a 10) os sistemas se caracterizaram por uma alta intensidade, tendo-se observado uma grande concentração mais ao Sul do Estado, indicando a presença de um bloqueio que impediu a passagem das frentes (Duquia, 1994).

Nos dias 13 e 14 de maio de 1992 foram monitorados diversos núcleos de nebulosidade com precipitações intensas sobre as regiões Sul e Oeste do Estado, quando iniciou-se o processo que elevou o índice médio do mês de maio de $101,4 \mathrm{~mm}$ para $500,0 \mathrm{~mm}$ na bacia a montante de União da Vitória e de 110,00 mm para 523,6 mm à jusante deste local. O quadro agravou-se a partir do dia 26 de maio, quando uma frente fria ficou semi-estacionária sobre a bacia do rio Iguaçu. A precipitação mais elevada $(259,7 \mathrm{~mm})$, acumulada em 24 horas, foi registrada no posto pluviométrico do município de Pinhão, onde fica localizada a usina hidrelétrica de Foz do Areia (Duquia, 1994).

O número de dias em que os sistemas frontais atuaram no período 1974-1992 correspondem em média a 10 dias de duração, desde o início da formação da frente até a sua propagação para outras regiões. Dentro deste período, cinco dias podem ser considerados de chuvas intensas, responsáveis pelas cheias na região. Em média o número de sistemas frontais em um mês é cinco, e o critério foi maximizar o mais intenso (Duquia, 1997). Com base nestas observações, ajustou-se uma distribuição exponencial de dois parâmetros às máximas intensidades de cinco dias de duração.

Como o único posto pluviométrico antigo na bacia intermediária é União da Vitória (dados a partir de 1938) foi necessário calcular a chuva média introduzindo duas estações situadas fora da bacia em estudo, Guarapuava e Palmas, ambas com dados a partir de 1925. Estudos anteriores mostraram que o uso destas estações para o cálculo da chuva média não apresenta diferenças significativas do que quando calculada apenas com dados dentro da bacia (Sugai, 1980; Sugai et al., 1985).

As equações abaixo, para o cálculo da chuva média, correspondem respectivamente aos períodos 1925-1937; 1938-1945 e 1946-1992, este último quando entrou em operação a estação de Jangada.

$$
\begin{gathered}
\overline{\mathrm{P}}=0,5770 \mathrm{P}_{\mathrm{GU}}+0,4230 \mathrm{P}_{\mathrm{PA}} \\
\overline{\mathrm{P}}=0,2299 \mathrm{P}_{\mathrm{GU}}+0,0385 \mathrm{P}_{\mathrm{PA}}+0,7316 \mathrm{P}_{\mathrm{UV}} \\
\overline{\mathrm{P}}=0,2299 \mathrm{P}_{\mathrm{GU}}+0,0063 \mathrm{P}_{\mathrm{PA}}+0,3445 \mathrm{P}_{\mathrm{UV}}+0,4193 \mathrm{P}_{\mathrm{JG}}
\end{gathered}
$$

onde: $\overline{\mathrm{P}}$ - precipitação média, de cinco dias de duração, na bacia incremental; $\mathrm{P}_{\mathrm{GU}}$ - precipitação em Guarapuava; $\mathrm{P}_{\mathrm{PA}}$ - precipitação em Palmas; PUv - precipitação em União da Vitória; $\mathrm{P}_{\mathrm{JG}}$ - precipitação em Jangada.

O modelo estatístico usado, para a obtenção das máximas intensidades de cinco dias de duração, foi a distribuição exponencial de dois parâmetros, os quais foram estimados pelo método da máxima verossimelhança. Estudos feitos no Centro de Pesquisas de Energia Elétrica - CEPEL têm recomendado esta distribuição para o ajuste a amostras com assimetria próxima ou superior a 2,0 (Kelman, 1983). No caso o coeficiente de assimetria é 2,3. Foi ajustada uma distribuição deste tipo aos dados com bons resultados.

A simulação da operação do reservatório foi feita da seguinte forma: i) adotou-se a mesma distribuição temporal dos eventos de 1983 e 1992; ii) maximizaram-se as chuvas intermediárias (5 dias), considerando-se diversas probabilidades de ocorrência. Para o evento de 1983, com um período de retorno estimado em 155,4 anos, as chuvas intermediárias foram maximizadas supondo-se riscos de ocorrência de 500 anos e 1000 anos na bacia incremental. Para 
o evento de 1992, com um período de retorno estimado em 33,3 anos, maximizaram-se as chuvas intermediárias para a mesma recorrência do evento de 1983 e para 500 anos de período de retorno.

Os resultados obtidos, para os dois eventos, permitiram concluir que os níveis operacionais não são sensíveis ao risco de ocorrência de uma chuva intensa na bacia intermediária entre União da Vitória e Foz do Areia.

Operação no nível máximo normal de projeto -

Para verificar a possibilidade de operar o reservatório no nível máximo normal estabelecido pelo projeto $(744,0 \mathrm{~m})$, foi necessário considerar que as seguintes melhorias sejam viáveis: i) ampliar o alcance das previsões de chuva; ii) obter boas previsões quantitativas de chuva para esse alcance; iii) aprimorar o sistema de previsão de vazões em União da Vitória, através da abordagem determinística aqui estudada.

Em resumo, isso significa, aprimorar o sistema de previsão de afluências ao reservatório de Foz do Areia através de boas previsões quantitativas de chuva de mesoescala, que possam ser incorporadas ao modelo hidrológico, e estender o método proposto a toda a bacia a montante de União da Vitória, eliminando desta forma as inadequações provenientes dos modelos ARIMA para prever o trecho de subida dos hidrogramas, inadequação que se acentua à medida que aumenta o horizonte das previsões. Para simular este sistema de previsão quase perfeito, algumas hipóteses foram aceitas:

i as previsões de vazões em União da Vitória $(48 \mathrm{~h} \mathrm{e}$ $72 \mathrm{~h}$ ) foram feitas iguais às previsões para alcances de 12 horas de antecedência obtidas com os modelos ARIMA;

ii. supôs-se que a chuva futura é conhecida.

Os eventos de 1983, 1990 e 1992 foram simulados partindo-se do reservatório cheio, operando na cota $744,0 \mathrm{~m}$ Sempre que a previsão de vazões em União da Vitória era igual ou superior a $800,0 \mathrm{~m}^{3} \mathrm{~s}^{-1}$, redefinia-se o nível máximo operacional dentro do horizonte de previsão (cota 742,0 m); critério este que foi estabelecido por tentativas.

Observou-se que a restrição de montante foi violada apenas durante 9 h, e o nível em União da Vitória ultrapassou a cota de desapropriação urbana em apenas $4 \mathrm{~cm}$. Também observou-se que não houve rompimento da restrição de nível em União da Vitória para a cheia de 1992. Por outro lado, para o evento de 1990 (Figura 16), com probabilidade de ocorrência bem maior que os anteriores, verificou-se que a restrição de montante foi violada durante 154 h (6,4 dias) e os níveis em União da Vitória foram influenciados em $17 \mathrm{~cm}$ com relação à operação real (nível máximo na cota $742,0 \mathrm{~m}$ ). Procurou-se elevar o horizonte de previsão para 72 horas e a influência máxima nos níveis em União da Vitória passou a ser de $9 \mathrm{~cm}$. Note-se que, em nenhuma das situações simuladas, analisou-se os prejuízos que o rebaixamento do nível máximo de operação (no mínimo $2 \mathrm{~m}$ em 48 horas) venha causar à jusan-

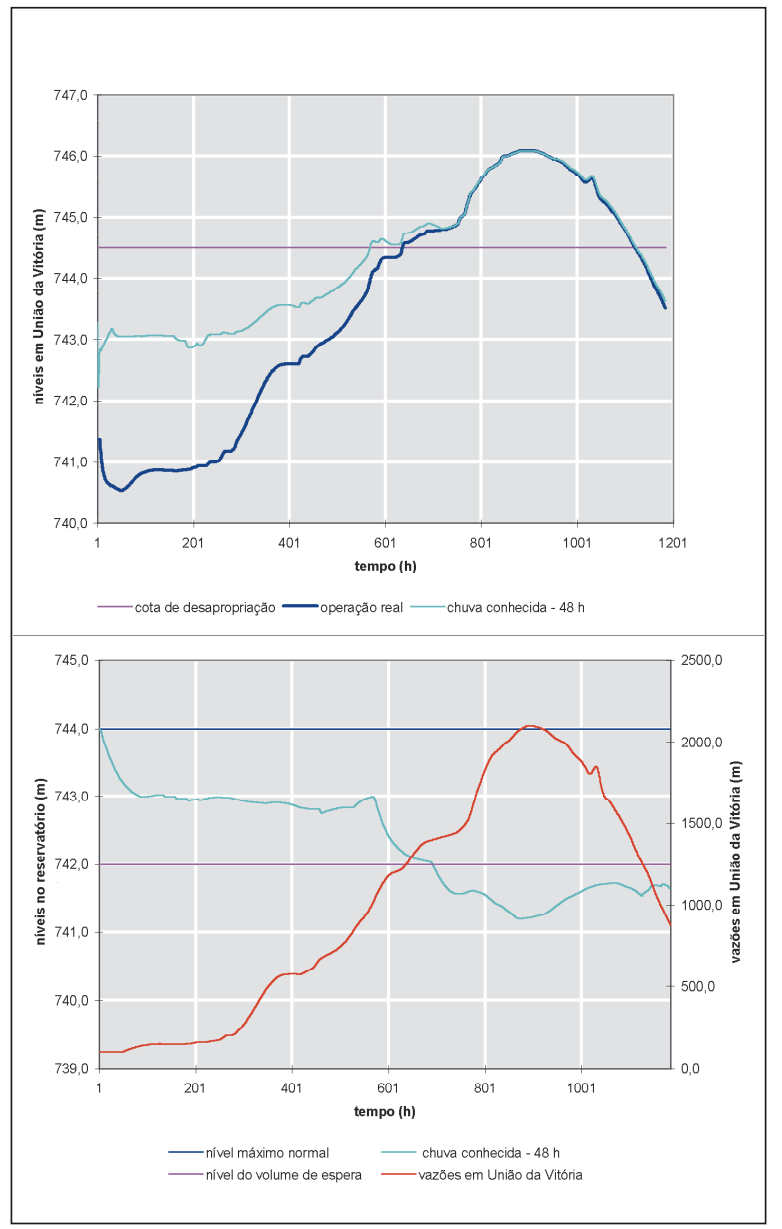

Figura 16. Simulação com nível máximo normal na cota 744,0 m - evento de 1990.

te, uma vez que a usina de Foz do Areia foi tratada como um sistema isolado.

Benefícios da previsão de afluências na operação - Os benefícios da previsão de afluências em tempo real foram avaliados nos seguintes termos: i) obter maior segurança no controle de cheias, tanto incorporando previsões quantitativas de chuva no modelo hidrológico quanto admitindo que a chuva pare no tempo da previsão; ii) obter um aumento da capacidade de geração do sistema.

Beneficio quanto ao controle de cheias: Somente para as cheias de 1983 e 1990 foi possível simular os níveis do reservatório incorporando as chuvas previstas pelo modelo estocástico ARMA (1,1), uma vez que as precipitações horárias dos demais eventos foram usadas para estimá-lo.

As previsões de afluências foram feitas para um alcance de 24 horas de antecedência, incorporando previsões de chuva para um alcance de $12 \mathrm{~h}$ e atualizadas de $4 \mathrm{~h}$ em $4 \mathrm{~h}$. Estes horizontes ( $12 \mathrm{~h}$ para chuvas e $24 \mathrm{~h}$ para vazões) foram escolhidos, tendo em vista os resultados anteriores, de que os níveis são praticamente os mesmos quer as pre- 
visões sejam feitas com chuva conhecida ou chuva zero, em função do tempo de concentração da bacia incremental. Logo, espera-se poder operar o reservatório com um horizonte de previsão de $24 \mathrm{~h}$ desde que possam ser feitas boas previsões de chuva para mais $12 \mathrm{~h}$.

Apesar do modelo de previsão de chuvas não ter fornecido resultados satisfatórios, a sua utilização resultou em uma operação mais segura da cheia de julho de 1983, quando comparada com a operação real, conforme exemplificado no gráfico da Figura 17, que relaciona as operações real (sem previsão de chuva), com chuva žero e chuva prevista pelo modelo estocástico.

Resultados satisfatórios e melhores que os apresentados na Figura 17 foram obtidos quando simulou-se a operação do reservatório para um horizonte de previsão de afluências de 12 horas e chuva zero. $\mathrm{Na}$ operação real, a previsão de afluências, na bacia intermediária, é feita para cada quatro horas de antecedência, através de um modelo muito simples, chamado previsor persistente, no qual, a vazão do último intervalo de tempo será igual a do próximo intervalo (Mine, 1980).

Beneficio quanto ao aumento da capacidade de geração: A energia gerada é proporcional à vazão turbinada e à queda líquida, dada pela diferença entre o nível de montante e o de jusante, este último acrescido da perda de carga no conduto forçado.

Logo, para calcular o benefício do método proposto em termos de um aumento na capacidade de geração da usina, determinou-se a energia gerada para cada uma das cheias estudadas e para as duas regras operacionais. Para que os resultados obtidos para as duas regras pudessem ser comparáveis, foi necessário adotar o mesmo critério para determinação das vazões turbinadas.

O nível de montante para as duas regras operacionais, atual e proposta, é conhecido e o nível de jusante, para as duas condições, foi determinado considerando-se a curva de descarga do canal de fuga correspondente ao reservatório de Segredo (situado à jusante), operando no nível máximo normal $(607 \mathrm{~m})$, uma vez que somente eventos de enchente foram analisados. A vazão defluente para a regra proposta foi calculada neste trabalho e a vazão defluente real (regra atual) foi obtida por balanço hídrico.

A Tabela 5 apresenta o aumento da capacidade de geração em MWh/evento, onde observa-se que houve ganho energético para todas as cheias estudadas.

Apesar da avaliação do aumento da capacidade de geração ter sido feita somente para os maiores eventos que ocorreram após a implantação do reservatório, quando a disponibilidade hídrica é abundante, representa um indicativo de que o benefício de longo prazo pode ser importante, considerando-se as cheias de um ano. Supondo a ocorrência de uma cheia por ano e um aumento médio de geração de $28150 \mathrm{MWh} /$ evento, obtido da Tabela 5, ter-se-ia um ganho energético de aproximadamente US $\$ 1.000 .000,00 /$ ano, adotando o custo médio do MWh igual a US\$35,50. Por outro lado, na fase atual, qualquer aumento da capacidade energética é importante, tendo em vista as limitações do parque gerador nacional.

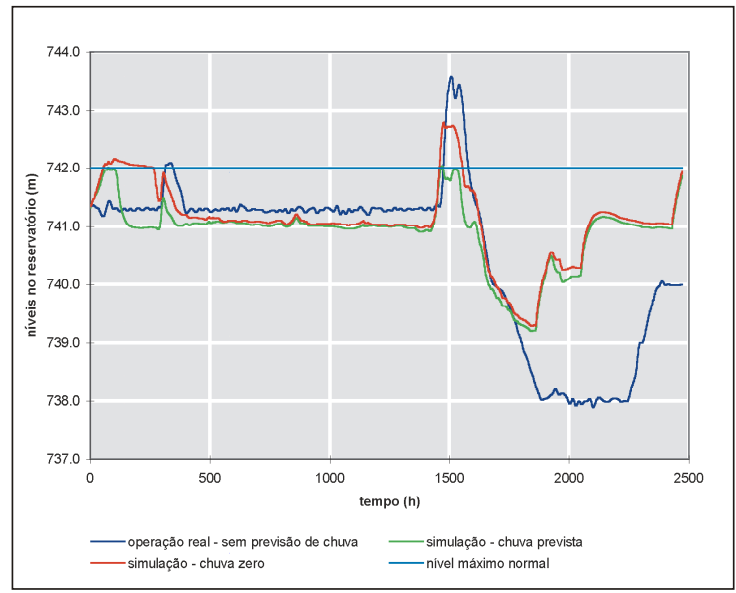

Figura 17. Níveis para diferentes previsões de chuva evento de $1983-\mathrm{HP}=24 \mathrm{~h}$.

Tabela 5. Aumento da capacidade energética em MWh/evento.

\begin{tabular}{crrr}
\hline Evento & \multicolumn{2}{c}{$\begin{array}{c}\text { Energia gerada em } \\
\text { MWh/evento }\end{array}$} & $\begin{array}{c}\text { Acréscimo } \\
\text { MWh/evento }\end{array}$ \\
& Regra proposta & Regra atual & \\
\hline 1982 & 1.351 .136 & 1.343 .137 & 7.999 \\
1983 & 3.701 .725 & 3.698 .303 & 3.422 \\
1987 & 1.043 .443 & 1.041 .318 & 2.125 \\
1990 & 946.651 & 945.505 & 1.145 \\
1992 & 1.438 .146 & 1.318 .967 & 119.179 \\
1993 & 1.273 .663 & 1.220 .283 & 53.380 \\
1995 & 1.342 .059 & 1.332 .239 & 9.820 \\
& & & \\
Total & 11.096 .823 & 10.890 .752 & 197.070 \\
\hline
\end{tabular}

Outro fator relevante corresponde a uma possivel complementaridade hídrica entre as regiões Sudeste e Sul do Brasil; esta última podendo estar com os reservatórios cheios no inverno, devido ao seu regime hidrológico indefinido, e portanto, podendo fornecer mais energia para o Sudeste. Este assunto tem sido motivo de preocupação recente pelas empresas do Setor Elétrico, e alguns estudos preliminares já foram empreendidos pelo CEPEL e pela própria COPEL.

\section{CONCLUSÕES}

Os reservatórios para geração hidrelétrica são gerenciados com base em volumes afluentes provenientes de um processo natural incerto. Logo, o risco na operação é inevitável, contudo, pode ser diminuído, combinando ferramentas matemáticas e técnicas computacionais com boas informações hidrometeorológicas.

O método apresentado combina as ferramentas acima e é geral pelo fato de que pode ser aplicado para buscar 
a eficiência operacional de qualquer reservatório para geração hidrelétrica. No entanto, é particularmente atraente para reservatórios situados em regiões onde a estação chuvosa não é definida. A região Sul do Brasil caracteriza um exemplo importante, onde os registros históricos têm mostrado que ocorrem cheias tanto nos meses de verão como de inverno, e que as enchentes catastróficas ocorrem nesta última estação do ano. Logo, torna-se difícil alocar volumes de espera, conforme métodos estatísticos usuais, no início de uma possível estação chuvosa no inverno, uma vez que se pode estar correndo o risco de não ser possível recuperar o reservatório, caso eventos extremos não venham a ocorrer. Observe-se que o El Niño pode ser um indicativo de invernos chuvosos na região Sul do Brasil, por outro lado, o fenômeno ainda não é totalmente conhecido por parte da comunidade científica meteorológica mundial, para servir de critério para decisão de criar volumes para controle de cheias.

Visando minimizar esse problema, procurou-se, neste trabalho, aprimorar um modelo semi-conceitual de previsão de afluências a reservatórios de geração hidrelétrica, em tempo real, de tal forma a conciliar, de maneira mais eficiente, o conflito entre geração de energia e controle de cheias.

As previsões de afluências, juntamente com as restrições físicas e operacionais do reservatório em que o estudo de caso foi aplicado, permitiram definir uma regra operacional, que cria, em tempo real, um volume de espera para o controle de cheias.

Os dados, atualmente disponíveis para o local do estudo, possibilitaram analisar um leque de situações diversas, tanto no que concerne à previsão de cheias para diversos horizontes de previsão, como a incorporação da previsão quantitativa da chuva no processo de simulação hidrológica, mostrando a importância destas previsões nos níveis de água no reservatório. As principais conclusões e recomendações das diversas etapas realizadas no estudo são apresentadas na seqüência.

\section{Previsão de chuva}

A escolha dos modelos ARMA de baixa ordem, para previsão quantitativa de chuva, foi feita com base em dois fundamentos: teórico e prático. O uso de modelos ARMA para representar processos altamente não lineares (chuvas horárias) justifica-se teoricamente, com base nas semelhanças entre a sua estrutura de correlação e a de modelos baseados no processo de Poisson, estes últimos, consagrados na literatura, como capazes de representar satisfatoriamente as séries de precipitação. A praticidade para uso operacional é sem dúvida indiscutível, pois são facilmente integrados aos modelos hidrológicos de previsão de afluências, permitindo, inclusive, que as previsões de chuva sejam atualizadas em tempo real à medida que novas informações são recebidas.

Apesar da fundamentação teórica exposta acima, não foi tão simples identificar os modelos ARMA para previsão quantitativa de chuva de curto prazo, devido ao acentuado caráter não estacionário das chuvas horárias, que seguem distribuições assimétricas e truncadas em zero, conseqüência do grande número de dias sem chuva.

Como os modelos ARMA são válidos para processos estacionários com distribuição marginal normal, recorreuse a uma transformação Box-Cox na série original. Os resultados da previsão foram insatisfatórios, mesmo para o alcance de um intervalo de tempo à frente (1 hora), tendo apresentado ainda, o inconveniente de não ser possível obter previsões para horizontes de tempo maiores.

Trabalhando com a série original, foi possível fazer previsões para horizontes diversos, mas sabe-se, a priori, que o modelo não satisfaz completamente à teoria das séries temporais dos processos ARMA, sendo utilizado somente para mostrar que, mesmo com previsões quantitativas de chuva de má qualidade, pode-se controlar cheias com maior segurança do que supondo que a chuva cesse no tempo da previsão, destacando-se, desta forma, a sua importância na operação de reservatórios.

Caso estes modelos venham a ser utilizados, é necessário buscar transformações mais adequadas para os dados originais, o que deixou de ser feito neste trabalho, uma vez que o objetivo não era prever chuva, mas utilizá-la no contexto de operação de reservatórios, mostrando que ocupa lugar de destaque, e portanto, merecedora de muitos estudos futuros. Este objetivo foi plenamente cumprido, uma vez que foi possível mostrar que com um modelo de previsão de chuvas, tão simples como o aqui apresentado, poder-se-ia ter operado o reservatório de Foz do Areia de maneira mais eficiente quanto ao controle de cheias, durante o episódio de 1983.

Entretanto, o ideal é que as previsões de chuva sejam fundamentadas no conhecimento dos fenômenos meteorológicos e em uma vasta informação de dados meteorológi$\cos$ de alta qualidade. Isto exige, por parte da comunidade científica, um grande esforço, tanto em pesquisas quanto na disponibilização dessas previsões em tempo real, armazenando-as em seguida, de tal forma que os hidrológos possam dispor de um banco de dados de previsões meteorológicas, pelo menos as referentes aos eventos de maior magnitude, o que certamente possibilitará que avaliem de forma mais efetiva o efeito da sua integração com os modelos hidrológicos de previsão de afluências.

\section{Simulação e previsão da contribuição lateral}

Para determinar a contribuição lateral na bacia em estudo, utilizou-se o modelo IPH II, que foi aplicado de forma semi-distribuída em onze sub-bacias, procurando-se com isto levar em conta a diversidade de características físicas e a variabilidade espacial da chuva.

Foram consideradas duas diferentes densidades de pluviômetros: 28 pluviômetros (exceto no caso de falhas) e quatro pluviômetros, escolhidos próximos de locais onde foram instaladas recentemente estações automáticas de dados, visando analisar o comportamento do modelo com a utilização somente destas informações. Percebeu-se que 
o uso de uma rede mais densa, conduziu, na fase de simulação, a vazões instantâneas melhores, no entanto, a perda de qualidade, em termos de volumes afluentes previstos em um intervalo de tempo não foi significativa com o uso de uma densidade menor. Os resultados sugerem, no entanto, um novo ajuste dos parâmetros do modelo para diferentes densidades de estações, caso o interesse esteja centrado no valor da previsão pontual da vazão.

Ressalta-se que esses resultados podem ser válidos somente para a região em estudo, por tratar-se de aplicação em uma bacia rural de tamanho médio (bacia intermediária) em clima subtropical úmido, onde percebe-se uma certa uniformidade na distribuição espacial da chuva, para os eventos maiores, podendo estas conclusões não permanecerem para outras regiões.

Quando o modelo foi aplicado para previsão de afluências ao reservatório, usando-se diferentes densidades, percebeu-se, em geral, picos mais altos para baixa densidade de pluviômetros e mesmo conjunto de parâmetros; mas a relação entre volumes observados e previstos foi praticamente a mesma, e muito próxima da unidade, quando se supôs conhecer a chuva futura.

As conclusões acima permitem dizer que as previsões de afluências à Foz do Areia podem ser feitas utilizando-se somente chuvas provenientes da rede automática de dados, apesar de se saber que, a estimativa da chuva média na bacia, através de um número pequeno de estações, tem uma variância maior que quando estimada a partir de um número infinito de pontos dentro da bacia. Logo, é ideal que o sistema de alerta tenha diversas calibrações do modelo, que atendam a todos os possíveis cenários de disponibilidade de dados, inclusive informações provenientes do radar meteorológico, atualmente em fase de instalação.

A variabilidade temporal da chuva foi levada em conta, desagregando-se todas as informações disponíveis para a escala horária de tempo, em função de um único pluviógrafo existente na bacia. Claramente, este procedimento é muito aproximado, mas foi preciso, devido à necessidade de se trabalhar com curtos intervalos de tempo, conseqüência da resposta rápida da bacia incremental em estudo. Esta questão poderá ser resolvida, incorporando-se ao modelo a variabilidade temporal fornecida pelas estações com transmissão automática de dados.

Quanto a tratar o modelo de modo adaptativo, não se recomenda atualizar os parâmetros do modelo semiconceitual, uma vez que na aplicação semi-distribuída, o número desses parâmetros é muito grande, e esta atualização torna-se impraticável para fins operacionais. Neste trabalho, apenas o estado do sistema foi atualizado, incorporando-se as últimas observações e executando novamente o modelo. No entanto, o IPH II permite a atualização do teor de umidade do solo, o que se traduz em um aumento da precisão nas previsões realizadas para os intervalos seguintes. Este é um procedimento ideal para simulação contínua, uma vez que no início do evento o estado de umidade do solo está atualizado adequadamente. Aqui, este recurso não foi usado, porque o modelo foi calibrado e aplicado por eventos, o que inviabilizou a verificação da efetividade deste procedimento de atualização do estado do sistema.

Em termos globais, o desempenho do modelo IPH II em simular a contribuição lateral da bacia incremental, e em conseqüência, prever volumes afluentes ao reservatório foi muito bom. Alguns resultados insatisfatórios obtidos foram devidos a problemas de erros de observação nos dados de chuva, inadequações do critério de desagregação temporal, baseado em um único pluviógrafo e representatividade espacial da chuva para os eventos menores.

Foi necessário adicionar às previsões de afluências na bacia intermediária as previsões de vazões na seção de montante, feitas através de modelos ARIMA, justificáveis, neste caso, devido ao amortecimento lento da onda de cheia até esta seção do rio. No entanto, poder-se-ia melhorar o alcance das previsões de afluências, caso a modelagem hidrológica determinística tivesse sido aplicada a toda bacia hidrográfica, a montante da seção da barragem.

\section{Simulação da fase canal}

O modelo hidrodinâmico de propagação em canal não apresentou os resultados esperados e algumas dificuldades foram encontradas durante a fase de aplicação, às quais foi dado um tratamento particular. Perceberam-se oscilações nas vazões simuladas para as seções dentro do reservatório e a solução numérica tornou-se instável para três das cheias estudadas, quando o controle hidráulico existente no rio é afogado pelo remanso do reservatório.

Aceita-se que essas oscilações possam ser devidas à grande variação da forma do rio que rompe as condições de uniformidade das equações diferenciais, à forte não linearidade do sistema e à imprecisão dos níveis observados no reservatório.

Para resolver a questão da instabilidade numérica devido à mudança de regime de escoamento, utilizou-se o fato de que o módulo canal do modelo IPH IV permite introduzir uma barragem interna à discretização. Foram realizados estudos em regime permanente, de tal forma a se definir a curva de descarga do vertedouro natural com afogamento à jusante.

O fato do modelo ter sido calibrado somente com base nas duas maiores cheias e aplicado para todas as demais foi uma das causas da simulação não ter se adequado de maneira satisfatória aos dados observados, e portanto, caso haja interesse na aplicação futura do modelo, o ajuste deverá ser revisto, contemplando os eventos menores.

Em virtude das condições hidráulicas do escoamento e das características de relevo da região, não houve necessidade de se usar o modelo hidrodinâmico para previsão de afluências ao reservatório, tendo sido usado, somente, com o objetivo de verificar se a restrição de montante do reservatório foi respeitada, cumprindo com este objetivo. 


\section{Simulação da operação}

O modelo de previsão de afluências proposto foi aplicado, juntamente com as restrições físicas e operacionais da usina, para otimizar os níveis visando o controle de cheias e o aumento da capacidade energética do sistema.

Para todos os eventos verificou-se que, quando a simulação foi feita para horizonte de previsão de 12 horas com chuvas conhecida e zero, os níveis operacionais foram praticamente os mesmos, concluindo-se que este fato está associado ao tempo de concentração da bacia incremental entre União da Vitória e Foz do Areia, estimado em 12 horas. Logo, se o operador do reservatório dispuser de previsões de chuva para mais 12 horas, poderá operá-lo com uma antecedência de 24 horas.

Simulações foram efetuadas para dois horizontes de decisão ( $2 \mathrm{~h}$ e $4 \mathrm{~h}$ ), concluindo-se que é suficiente que as decisões sejam tomadas de $4 \mathrm{~h}$ em $4 \mathrm{~h}$ e que o estado do sistema também seja atualizado para este horizonte de decisão.

Para que o nível máximo operacional possa ser elevado acima da cota 742,0 m, é necessário ampliar o alcance das previsões de afluências ao reservatório, estendendo a abordagem determinística a toda a bacia hidrográfica em questão, e introduzindo previsões meteorológicas de chuva de mesoescala. Desta forma, elimina-se a inadequação dos modelos ARIMA, que fazem previsões atrasadas com relação ao hidrograma observado, inadequação esta que se acentua com o aumento do alcance da previsão. Por outro lado, surge a questão da confiabilidade das previsões de chuva e a necessidade de uma desagregação temporal e espacial à escala da bacia hidrográfica. Com um tal sistema de previsão de chuvas, poder-se-á criar volumes de espera em tempo real de médio prazo, evitando desta forma adotar medidas operacionais de última hora, correndo-se o risco de romper restrições operacionais.

A regra operacional definida foi avaliada quanto à sua eficiência em atender possíveis condições de níveis altos no reservatório combinados com chuvas de altos períodos de retorno na bacia intermediária, tendo-se mostrado totalmente satisfatória, não colocando, portanto, em risco a segurança da barragem, caso eventos de grandes magnitudes venham a ocorrer.

A simulação da operação, feita para diversos horizontes de previsão e decisão, e também diversas previsões de chuva, apresentou resultados satisfatórios sobretudo quanto ao controle de cheias, mostrando que é necessário investir em novas tecnologias, e que é muito melhor apostar na incerteza da chuva, tanto em termos de quantidade como de distribuição espacial e temporal, e no empirismo dos modelos semi-conceituais e também na sua previsão, do que correr riscos maiores como, por exemplo, apostar na intuição de que a taxa de variação da vazão observada nas últimas horas se repita no futuro próximo, ou, pior ainda, acreditar que o processo natural de vazões afluentes possa ser representado por um previsor persistente, no qual, a vazão do próximo intervalo de tempo será igual a do último intervalo.
Por causa das características peculiares de Foz do Areia, com uma séria restrição operacional a montante, que impede que se eleve o nível máximo operacional, sabe-se $a$ priori, que os benefícios em termos do aumento da energia firme da usina não são significativos, mas assim mesmo, foram avaliados para os eventos estudados, tendo-se percebido um aumento na capacidade de geração em todos os casos. Contudo, é provável que esse aumento seja significativo, caso o método proposto venha a ser aplicado a toda a cascata de reservatórios do rio Iguaçu, da qual Foz do Areia é a primeira usina.

Em termos do controle de cheias o assunto voltou-se sobretudo em atender a segurança da população a montante do reservatório, e que pode, dependendo das condições operacionais, estar sujeita à influência do remanso. Conclui-se dos estudos realizados que é possível operar o reservatório com maior segurança utilizando-se o método proposto nesta tese, mesmo sem um sistema de previsão de chuvas, para um alcance de 12 horas de antecedência.

O trabalho teve o mérito de propor um sistema de previsão de afluências ao reservatório de Foz do Areia, muito melhor que o atualmente em vigor, também desenvolvido pela autora deste trabalho e portanto, conhecedora da sua precariedade.

Apesar da aplicação ter sido feita para um reservatório específico, considerado como isolado dentro do sistema interligado do parque gerador nacional, o sistema de previsão e controle, aqui apresentado, tem potencial para operar de forma eficiente um conjunto de reservatórios, independente das condições de regime hidrológico em que os mesmos estejam localizados. Evidentemente, o método fica prejudicado, se a qualidade dos dados for precária, quer na fase de ajuste dos modelos que compõem o sistema ou na fase de previsão e decisão em tempo real

\section{REFERÊNCIAS}

BERTHELOT, R. (1970). Curso de hidrologia sintética. Porto Alegre: IPH, 1970. Relatório técnico IPH, UFRGS.

BOX, G. P. \& JENKINS, G. M. (1976). Time series analysis forecasting and control. Oakland: Holden-Day, $575 \mathrm{p}$.

BURLANDO, P. et al. (1993). Forecasting of short-term rainfall using ARMA models. J. of Hydrology, v. 144, n. 1/4. p. 193 211. Apr.

COPEL (1995). Companhia Paranaense de Energia. Usina Hidrelétrica Foz do Areia, rio Iguaç, Paraná, Brasil. memória técnica. Curitiba: COPEL, $280 \mathrm{p}$.

CUNHA, L. M (1995). Apresentação da instrução da operação hidráulica dos reservatórios de Foz do Areia e Segredo. Curitiba: COPEL.

CUNHA, L. M. (1997). Comunicação verbal.

DUQUIA, C. G. (1994). Aspectos meteorológicos dos eventos ocorridos nos anos de 1983, 1992 e 1993. Curitiba: COPEL, abr.

DUQUIA, C. G. (1997). Comunicação verbal.

GCOI (1991). Grupo Coordenador para Operação Interligada. Subcomitê de Estudos Energéticos. Volumes de espera nos reservatórios do sistema interligado. Curitiba, out. (SCENGTHO-02/91). 
HORTON, R. E. (1937). Determination of infiltration capacity for large drainage basins. Transactions of the American Geophysical Union, v. 8: p. 371.

KELMAN, J. (1983). Controle de cheias e aproveitamentos bidrelétricos. Rio de Janeiro: UFRJ. 210 p. Tese (Titular), UFRJ.

MINE, M. R. M. (1980). Projeto HG-43. Previsão de cheias em Foz do Areia. Curitiba: Centro de Hidráulica e Hidrologia Prof. Parigot de Souza.

MINE, M. R. M. (1984). Modelos estocásticos lineares para previsão de cheias em tempo-real. São Paulo: USP. 127 p. Dissertação (Mestrado), USP.

MINE, M. R. M. (1986). Projeto HG-51. Análise bidrológica e matemática de operação de reservatórios: previsão de vazões de cheias em União da Vitória. Relatório no 2 . Curitiba, Centro de Hidráulica e Hidrologia Prof. Parigot de Souza.

MINE, M. R. M. (1998). Método deterministico para minimizar o conflito entre gerar energia e controlar cheias. Porto Alegre: UFRGS. (Tese de doutorado).

MINE, M. R. M. e TUCCI, C. E. M. (1999). Previsão em tempo real de vazões afluentes a reservatórios de usinas hidrelétricas. Revista Brasileira de Recursos Hídricos, Porto Alegre.

OBEYSEKERA, J. T. B., TABIOS III, G. Q., SALAS, J. D. (1987). On parameter estimation of temporal rainfall models. Water Resources Research, v. 23, n. 10, p 1837-1850, Oct.

SILVEIRA, C. A C. (1996). Previsão de volumes de espera em tempo real. Porto Alegre: UFRGS. 62 p. Dissertação (Mestrado), UFRGS/IPH.

SUGAI, M. R. von B. (1980). Influência do reservatório de Foz do Areia sobre niveis de enchentes em União da Vitória. Curitiba: COPEL. 53 p.

SUGAI, M. R. von B., MASSUCCI, L. A., BUSETI, D. C., SANTOS, A., F. (1985). Influência do reservatório de Foz do Areia sobre niveis de enchentes em União da Vitória: revisão e atualização. Curitiba: COPEL.

TUCCI, C. E. M., SÁNCHEZ, J., LOPES, M. O. S. (1981). Modelo IPH II de simulação precipitação-vazão na bacia: alguns resultados. In: Simpósio Brasileiro de Hidrologia e Recursos Hídricos, 4: Fortaleza. Anais. São Paulo: ABRH, v. 4 , p. $83-103$

TUCCI, C. E. M. e VILLANUEVA, A O N. (1997). Controle de enchentes das cidades de União da Vitória e Porto União. União da Vitória: CORPRERI, $117 \mathrm{p}$.

\section{Energy Production Management and Flood Control: Foz do Areia in the Iguaçu River}

\section{ABSTRACT}

Reservoir operation for power generation seeks to maximize the level and discharge, which may lead to conflicts upstream and downstream from the development, due to flooding. In order to manage these conflicting aims, a system is required to forecast reservoir inflow, integrated with its operation. This system should minimize the impacts of floods and maximize energy production.

In this study the methodology is presented to forecast the inflow combined with the operation of a Hydropower Plant that will fulfill both aims mentioned above. The methodology proposed uses an ARIMA model to forecast inflow from the basin upstream from the lake entrance, where the processes have a longer memory, and a semiconceptual model (IPH II rainfall-runoff model) for the part of the basin that drains directly into the reservoir lake. One of the major uncertainties in forecasting is that of the precipitation used in the abovementioned rainfall-runoff model. In this case, several alternatives were studied (a) rainfall ceases from the moment the forecast is made; (b) rainfall forecast is known; (c) a stochastic forecast of rainfall is used.

Together with forecasting, a reservoir operation model was developed which would allow the maximization of energy production and ensure the fulfillment of the safety operation restrictions of the reservoir and for the upstream and downstream population.

Although this methodology is used specifically for the Foz do Areia reservoir, it is a condition frequently found in various Brazilian power-generating reservoirs. In the case of Foz do Areia, on Iguach River, the results showed that the forecast made it possible to improve compliance with restrictions and the recovery of the reservoir levels.

Key Words: forecasting; real time; reservoir. 